\title{
Climate Projections for South America: RegCM3 Driven by HadCM3 and ECHAM5
}

\author{
Michelle Simões Reboita, ${ }^{1}$ Rosmeri Porfírio da Rocha, ${ }^{2}$ \\ Cássia Gabriele Dias, ${ }^{1}$ and Rita Yuri Ynoue ${ }^{2}$ \\ ${ }^{1}$ Federal University of Itajubá (UNIFEI) and Natural Resources Institute, Avenida BPS 1303, 37500-903 Itajubá, MG, Brazil \\ ${ }^{2}$ Department of Atmospheric Sciences, São Paulo University, Rua do Matão 1226, 05508-090 São Paulo, SP, Brazil
}

Correspondence should be addressed to Michelle Simões Reboita; reboita@unifei.edu.br

Received 20 December 2013; Revised 25 April 2014; Accepted 28 April 2014; Published 29 May 2014

Academic Editor: Luis Gimeno

Copyright (C) 2014 Michelle Simões Reboita et al. This is an open access article distributed under the Creative Commons Attribution License, which permits unrestricted use, distribution, and reproduction in any medium, provided the original work is properly cited.

\begin{abstract}
This study shows climate projections of air temperature and precipitation over South America (SA) from the Regional Climate Model version 3 (RegCM3) nested in ECHAM5 and HadCM3 global models. The projections consider the A1B scenario from Intergovernmental Panel on Climate Change (IPCC) and three time-slices: present (1960-1990), near- (2010-2040), and far-future (2070-2100) climates. In the future, RegCM3 projections indicate general warming throughout all SA and seasons, which is more pronounced in the far-future period. In this late period the RegCM3 projections indicate that the negative trend of precipitation over northern SA is also higher. In addition, a precipitation increase over southeastern SA is projected, mainly during summer and spring. The lifecycle of the South American monsoon (SAM) was also investigated in the present and future climates. In the near-future, the projections show a slight delay (one pentad) of the beginning of the rainy season, resulting in a small reduction of the SAM length. In the far-future, there is no agreement between projections related to the SAM features.
\end{abstract}

\section{Introduction}

Since the 1980s, scientific evidences have been published indicating changes in the global climate. The fourth (AR4, [1]) and fifth (AR5, [2]) Intergovernmental Panel on Climate Change (IPCC) reports state that "warming of the climate system is unequivocal..." and this conclusion is supported by observations of increase in global atmospheric and oceanic temperatures, melting of snow and ice, and sea level rise. Therefore, many questions about how the climate in different regions of the globe will be in the future arise. To this end, the IPCC defined several scenarios of greenhouse gases (GHG) emissions to be used in numerical studies. For AR4, the Special Report on Emissions Scenarios (SRES, [3]) defined a set of six-group scenarios derived from four families: A1, A2, $\mathrm{B} 1$, and $\mathrm{B} 2$, with $\mathrm{A} 2$ being pessimistic scenario with higher GHG emissions. These scenarios have been used in many numerical studies of future climate with both global and regional climate models (RCMs).

In South America (SA), Vera et al. [4] compared projections from seven global climate models (GCMs), using
A1B scenario for the period 2070-2099, and obtained a significant increase in precipitation from January to March over southeastern SA (SESA) and dry conditions in large part of the continent in winter (June to August). Bombardi and Carvalho [5] used the Model for Interdisciplinary Research on Climate (MIROC) to study the variability of the monsoon system over Brazil in a scenario with doubled $\mathrm{CO}_{2}$. The results did not show statistically significant differences related to the onset and length of the rainy season in the future period (2061-2080) compared to the present climate (19812000). However, in some regions such as the western Amazon an increase in precipitation during the rainy season was projected. Similar results were obtained by Bombardi and Carvalho [6] in the investigation of the lifecycle of the South American monsoon (SAM) for three time-slices (present: 1960-1990, near-: 2010-2040, and far-: 2070-2100 future climates) with the A1B scenario from ten IPCC-AR4 GCMs. Seth et al. [7] also investigated the annual cycle of SAM on the projections from nine GCMs from IPCC, but considering the A2 scenario. The authors reaffirmed previous results for the future climate such as increase in precipitation over SESA in 
summer and decrease in spring in the continental branch of the South Atlantic Convergence Zone (SACZ). According to Seth et al. [7], the precipitation positive trend in SESA can be associated with southward displacement of the South Atlantic Semi-permanent Anticyclone and intensification of eastern Andes low level jet. This latter feature would increase the transport of moisture from the tropics to the SESA. Valverde and Marengo [8] also evaluated five IPCC-AR4 GCMs future projections that indicate the displacement of the Chaco low to southeast of its climatological position, while in upper levels the Bolivia high displaces northwestward.

Due to the low horizontal resolution $(100-300 \mathrm{~km})$ of GCMs, regional-scale processes are not adequately solved. Thus, limited area models (RCMs, with $\sim 50 \mathrm{~km}$ of horizontal grid spacing or less) are an alternative to solve regional aspects of climate, especially those associated with circulations forced by topography or differences in surface coverage $[9,10]$. Thus, RCMs may also be very useful in various climate impact studies, such as agriculture, hydrology, health, architecture, and so forth. While GCMs need only initial conditions, RCMs need both initial and boundary conditions. RCMs simulations driven by GCMs outputs or analysis of observations are one method to downscale climate information. Using this method, Seth et al. [11] nested the Regional Climate Model (RegCM3) in the projections of the European Centre-Hamburg Model (ECHAM4.5). The authors obtained a more realistic representation of SA climate with the RegCM3 than with ECHAM4.5. In other words, the RegCM3 added important new information to the global model projections.

From previous studies with RCMs we highlight the efforts of CLARIS (Europe-South America Network for Climate Change Assessment and Impact Studies, [12]) and CLARISLPB (CLARIS-La Plata Basin [13]) projects to develop strategies for climate change and impact issues through a multi-scale integrated approach [12]. Both projects involved researchers working with different RCMs. Recently, in this context Solman et al. [13] evaluated the performance of seven RCMs (RCA, REMO, PROMES, RegCM3, MM5, LMDZ and Eta) in reproducing the mean climate conditions over SA, while Solman [14] synthetized the projections of these RCMs for future scenarios.

For the future climates, Marengo et al. [15] nested three RCMs (Eta/CPTEC, HadRM3P and RegCM3) in the projections of HadAM3 GCM with the A2 high emission scenario. In the future (2071-2100), air temperatures over SA may rise up to $4^{\circ} \mathrm{C}$ above the climatological average (19611990). For Amazon and north of northeastern Brazil it is projected a decrease in precipitation throughout the year, but for other SA regions there are no significant changes. These results are partially confirmed by Krüger et al. [16], which nested the RegCM3 in the HadAM3P projections for the A2 and B2 scenarios. These projections indicated a warming over SA, which in the A2 scenario can be higher than $5^{\circ} \mathrm{C}$ for the northeastern Brazil during summer. Both $\mathrm{A} 2$ and B2 scenarios show wet (dry) conditions over La Plata Basin (eastern Amazon and northeastern Brazil) in summer and dry conditions over south-central Brazil and western Amazon during the winter.
The climate projections with $\mathrm{A} 1 \mathrm{~B}$ scenario using EtaCPTEC RCM over SA driven by four members of HadCM3 GCM were analyzed by Marengo et al. [17]. In these projections temperatures increase by $4-6^{\circ} \mathrm{C}$ in central-northern Brazil. In addition, the North Atlantic trade winds weaken resulting in a decrease in precipitation over Amazon and northeast Brazil, while there are positive precipitation trends near the northern coast of Peru-Ecuador and SESA. The authors mention that the subtropical Atlantic high intensification may cause blocking or deceleration of cold fronts, explaining the decrease and increase in precipitation over the subtropics and mid-latitudes, respectively, for the future climate. Solman et al. [18] and Nuñez et al. [19] nested the MM5 in the projections of HadAM3 for two time-slices: 1981-1990 and 2081-2090. Both future scenarios (A2 and B2) projected a greater warming during spring in southern Brazil, Paraguay, Bolivia and northeastern Argentina. Moreover, it was projected an increase (decrease) in the precipitation over northern-central Argentina, especially in summer and fall (winter and spring).

Considering previous studies for the SA continent, we can synthesize the projections for the future climate as: for austral summer and winter there is an indication of an overall warming over the whole continent, but with higher temperature increase over the central Brazil. Regarding precipitation, the greater negative anomalies are also projected in central-northern Brazil, while over SESA in summer it is expected wetter conditions compared with present climate.

Since there are few studies that project the SA future climate based on RCMs and taking into consideration that these models add value to the GCMs (e.g., $[7,16])$, this work aims to investigate RegCM3 future projections of air temperature, wind and precipitation as well as SAM characteristics. For this, the RegCM3 was driven by two GCMs (HadCM3 and ECHAM5) for the A1B scenario and three time-slices (present: 1960-1990, near-future: 2010-2040, and far-future: 2070-2100). The paper is organized as follows: Section 2 describes the data and methodology; Section 3 presents the main results; and Section 4 brings the conclusions.

\section{Methodology}

Since the physical equations in climate models produce under present conditions a climate which resembles the observed one, it is reasonable to expect that the response to changes like concentration of greenhouse gases will look like the true (and unknown) response. However, before analyzing future climate it is necessary to evaluate the skill of dynamic models in the current climate. This study used the RegCM3 simulations performed within the context of the CLARIS-LPB [13]. First of all, we validated two simulations for the current climate (1960-1990) obtained from RegCM3 nested in the HadCM3 and ECHAM5 global models. Then, we analyzed projections of the future climate in two time-slices (2010-2040 and 2070-2100). A brief description of the GCMs and RegCM3 projections is given following. 
2.1. HadCM3 Projections. A detailed description of the Hadley Centre coupled model version 3 (HadCM3) and the procedures used to obtain the climate projections are presented in [20-22]. The projections of the HadCM3 have 19 vertical levels (hybrid vertical coordinate) and horizontal resolution of $2.75^{\circ}$ latitude by $3.75^{\circ}$ longitude. The projections extend from the pre-industrial era to the future (1860-2100) and consider the A1B, A2 and B1 greenhouse gases emission scenarios from IPCC (http://www.ipccdata.org/ar4/model-UKMO-HADCM3.html).

2.2. ECHAM5 Projections. ECHAM5 is a global spectral model from the Max-Planck-Institute for Meteorology and is described in detail by $[23,24]$. The ECHAM5 projections considering the $\mathrm{A} 1 \mathrm{~B}, \mathrm{~A} 2$ and $\mathrm{B} 1$ emission scenarios from IPCC (http://www.ipcc-data.org/ar4/model-MPIMECHAM5.html) used a T63 horizontal resolution (corresponding to the $1.875^{\circ} \times 1.875^{\circ}$ ) and 19 levels in the vertical, with top at $10 \mathrm{hPa}$.

2.3. RegCM3 and Characteristics of the Regionalized Simulations. The RegCM3 is a hydrostatic, compressible, and in the sigma-pressure vertical coordinate model. RegCM3 equations are discretized by the finite differences method in the Arakawa-Lamb B-grid. RegCM3 uses a split-explicit time integration scheme that solves the dynamics of the two fastest gravity modes using shorter time steps than the rest of the model components. RegCM3 also has an algorithm to reduce the horizontal diffusion in the presence of steep topography gradients [25, 26]. Pal et al. [27] present the main physical characteristics of RegCM3 including soil-plant-atmosphere interactions, radiative processes, turbulent heat fluxes and convective processes.

Six simulations were performed with RegCM3, three of them driven by HadCM3, and the other three by ECHAM5. Each set of the projections considered three time-slices: present climate (1960-1990), near-future (2010-2040) and far-future (2070-2100) for the A1B scenario from IPCC. The simulations were initiated one year before the referred period to allow adjustment of the hydrological cycle (spin-up period) as suggested by [28]. For simplicity, each time-slice of the RegCM3 projection will be referred only as RegHad (RegCM3 nested in HadCM3) and RegECHAM (RegCM3 nested in ECHAM5).

The domain of the simulations includes South America and part of the adjacent oceans (Figure 1) following the recommendation of the Coordinated Regional Downscaling Experiment (CORDEX; [29]). The simulations used $50 \mathrm{~km}$ of horizontal grid spacing, 18 sigma-pressure vertical levels, Biosphere-Atmosphere Transfer Scheme (BATS) to the surface physics [30] with modifications documented in [31], Holtslag parameterization to solve the planetary boundary layer process [32] and Grell with Fritsch-Chappell closure to the cumulus convection [33]. Topography and land use data were taken from the global files of the United States Geological Survey (USGS) and Global Land Cover Characterization (GLCC, [34]), respectively.

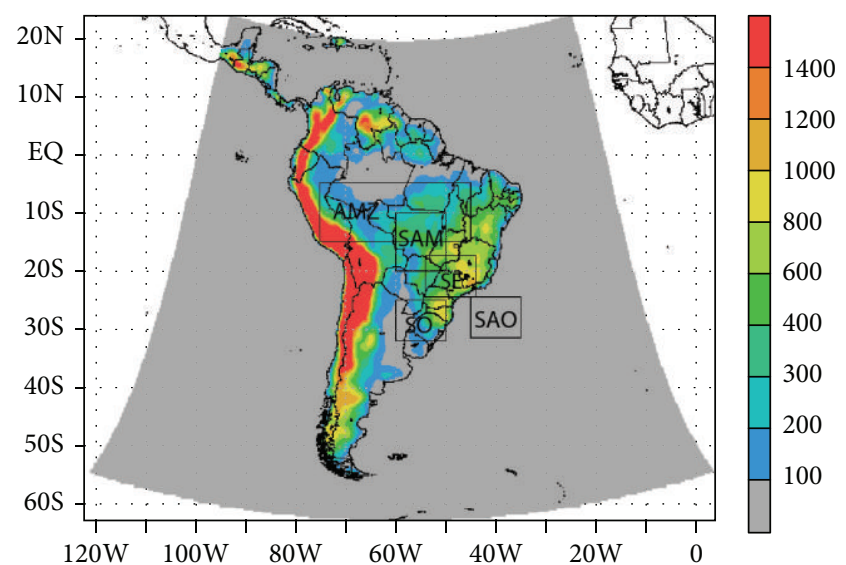

FIGURE 1: Subdomains used to validate the RegCM3 simulations: Amazon (AMZ), the area used in different studies to identify the lifecycle of the South American monsoon (SAM), southeastern Brazil (SE), southern Brazil (SO), and western South Atlantic Ocean (SAO). South America topography $(\mathrm{m})$ is also shown in the figure.

\subsection{Analyses of Simulations}

2.4.1. Air Temperature and Precipitation. For the present climate, the simulated air temperature and precipitation were validated by comparing with data from different sources: NCEP/NCAR reanalysis [35], ERA-40 reanalysis from the European Centre for Medium-Range Weather Forecasts (ECMWF; [36]), analysis from the Climatic Research Unit of the University of East Anglia (CRU; [37]), analysis from the Climate Prediction Center-Merged Analysis of Precipitation (CMAP; [38]) and from the University of Delaware (UDEL; [39]).

The analyses are conduced to the austral summer (DFJ) and winter (JJA) seasons for present climate and timeslices. For the present climate we compare the RegCM3 air temperature simulations with CRU analysis and NCEP reanalysis, while for precipitation we used CMAP instead of NCEP. Although CMAP time series (from 1979 to 1990) is shorter than the simulated one, it is able to show the main features of the climate. For the future scenarios we present the differences between the future (near and far) and present of the variables: $2 \mathrm{~m}$ air temperature, precipitation, and winds at $850 \mathrm{hPa}$.

The annual cycles of the air temperature and precipitation from RegCM3 simulations were also validated in five subdomains shown in Figure 1: Amazon (AMZ, $75^{\circ}-45^{\circ} \mathrm{W}$ and $15^{\circ}-5^{\circ} \mathrm{S}$ ), South American monsoon (SAM, $60^{\circ}-50^{\circ} \mathrm{W}$ and $\left.20^{\circ}-10^{\circ} \mathrm{S}\right)$, southern Brazil $\left(\mathrm{SO}, 60^{\circ}-50^{\circ} \mathrm{W}\right.$ and $32^{\circ}-25^{\circ} \mathrm{S}$ ), southeastern Brazil (SE, $54^{\circ}-44^{\circ} \mathrm{W}$ and $24.5^{\circ}-17.5^{\circ} \mathrm{S}$ ), and Southwestern Atlantic Ocean (SAO, $45^{\circ}-35^{\circ} \mathrm{W}$ and $31.5^{\circ}-$ $24.5^{\circ} \mathrm{S}$ ). The subdomain which represents AMZ followed the definition of [40] while the SAM subdomain was based on studies evaluating the SAM lifecycle, such as [31, 41].

2.5. South American Monsoon Lifecycle. A monsoon period means that most of the precipitation comprising the annual total in a given region occurs in summer [42]. In SA, besides 


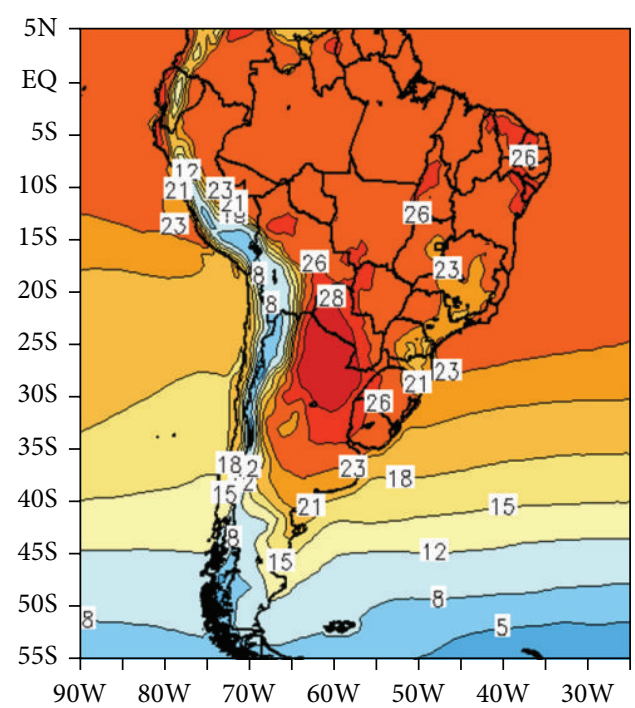

(a) RegHad, summer (1960-1990)

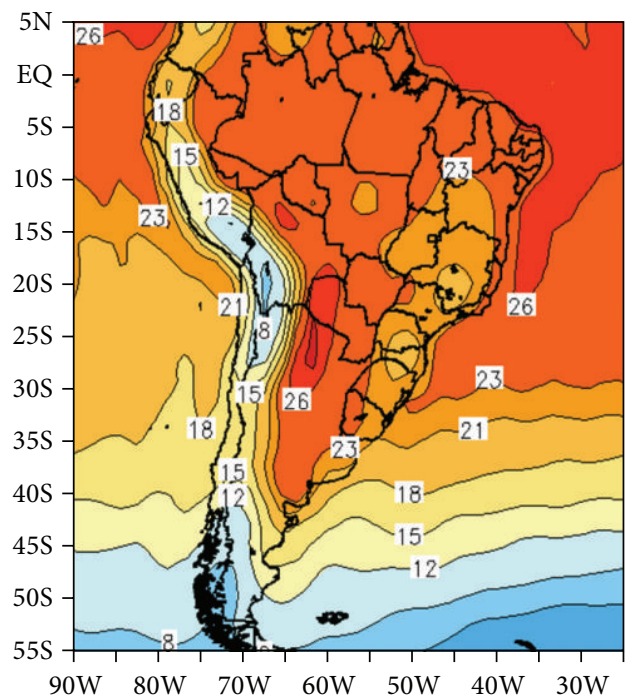

(c) NCEP, summer (1960-1990)

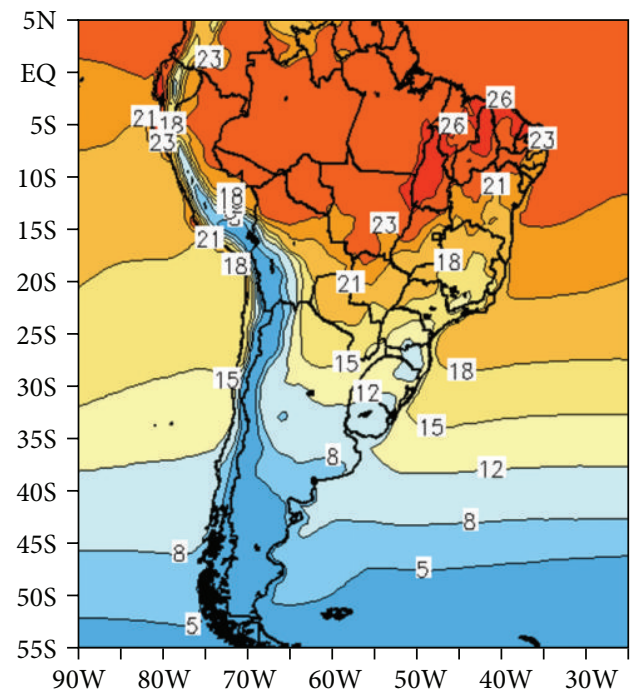

(e) RegHad, winter (1960-1990)

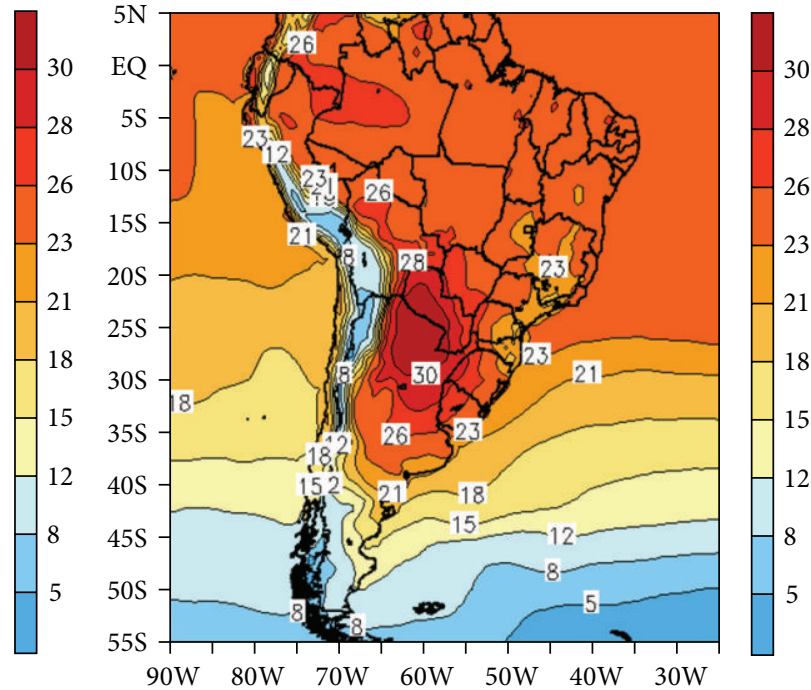

(b) RegECHAM, summer (1960-1990)

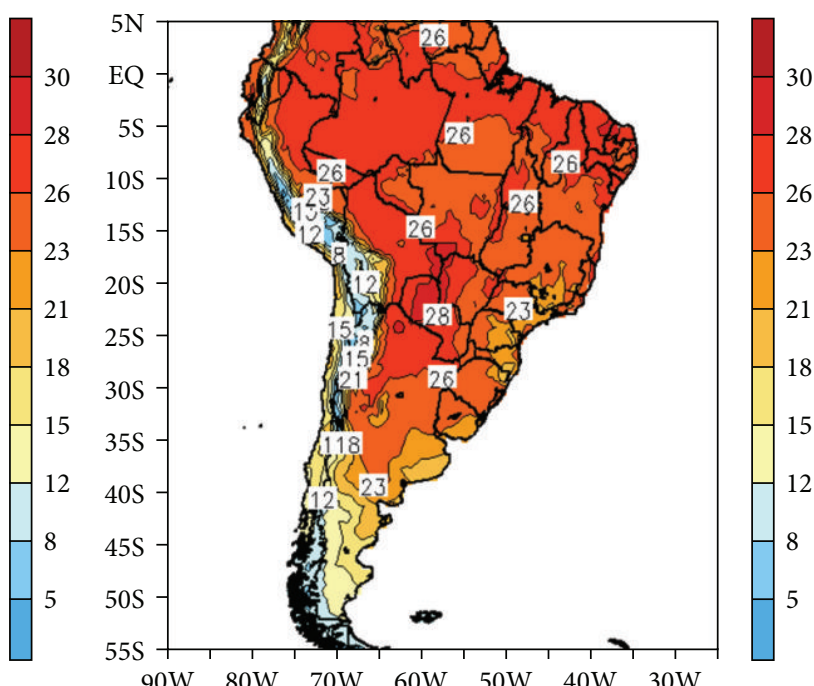

(d) CRU, summer (1960-1990)

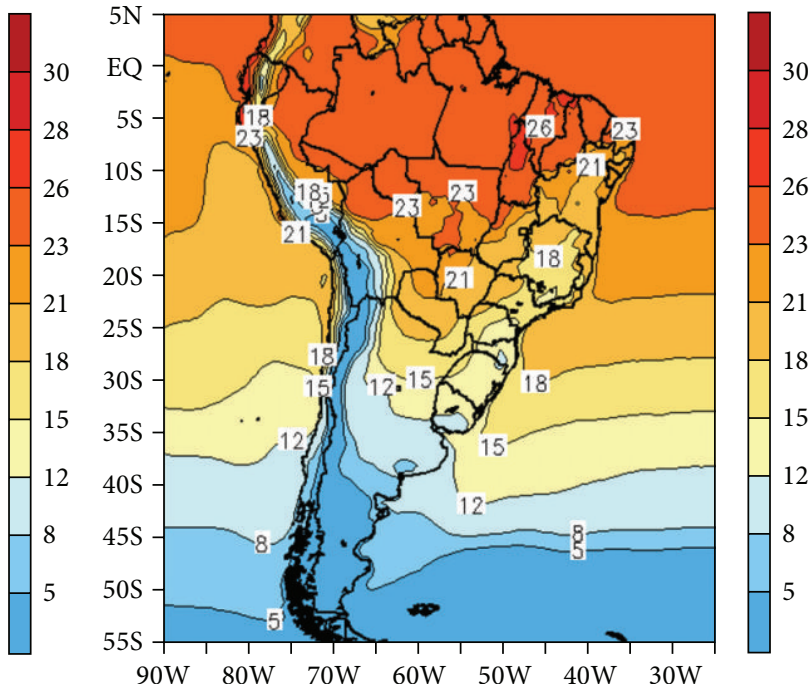

(f) RegECHAM, winter (1960-1990)

FIGURE 2: Continued. 


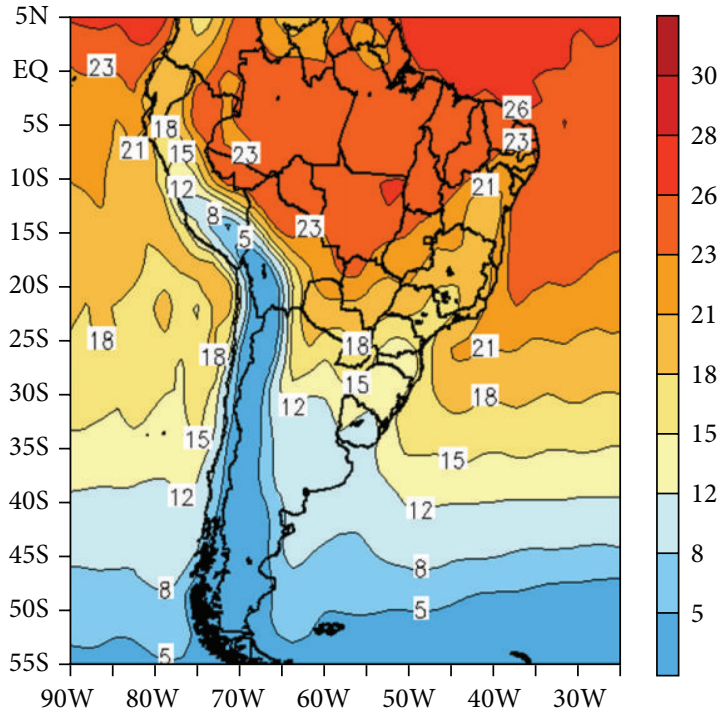

(g) NCEP, winter (1960-1990)

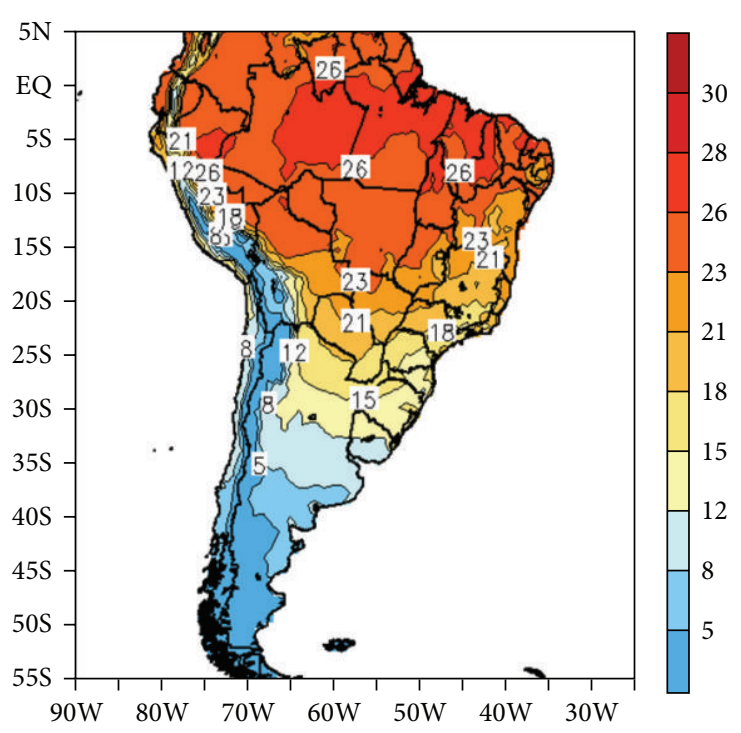

(h) CRU, winter (1960-1990)

Figure 2: Mean air temperature $\left({ }^{\circ} \mathrm{C}\right)$ in ((a)-(d)) summer and ((e)-(h)) winter from 1960 to 1990 in RegHad, RegECHAM, NCEP, and CRU.

the large amount of rainfall during summer, the monsoon period is also characterized by the intensification of the low levels northeasterly trade winds flowing from the North Atlantic Ocean to the continent, by the development at $200 \mathrm{hPa}$ of an anticyclonic system over Bolivia (Bolivia High) and a downstream trough located near the northeastern Brazil [43-46].

Several studies have determined the onset and demise of the rainy season on tropical and subtropical areas of SA (e.g., $[5,6,41,47,48])$. According to these authors, the SAM onset occurs at the end of August in the western sector of the Amazon. After that, the more intense rainfall migrates toward the subtropics and in mid-October occurs the establishment of the rainy season in this region. In the tropics (in the westcentral Brazil), the lifecycle (onset, demise, and duration) of the SAM may be defined by a precipitation index calculated using the thresholds for mean precipitation pentads over the SAM area (Figure 1) as proposed by Gan et al. [41] or the derivative of the accumulated precipitation as in Liebmann and Marengo [48]. The application of this last method is more appropriated for works that consider different time periods as is the case of the present study, since it does not impose any precipitation threshold. The method originally proposed by [48] and modified by [5] is

$$
S(\text { pentad })=\sum_{n=\text { pentad }_{1}}^{\text {pentad }}\left(R_{n}-\bar{R}\right),
$$

where $R_{n}$ is the precipitation in the $n$th pentad and $\bar{R}$ is the climatological average of all pentads of the period of study. The first pentad shown in the sum $\left(\right.$ pentad $\left._{1}\right)$ was chosen as the first pentad of the year (total precipitation from January 1 to January 5) which, in turn, is within the rainy season of the SAM region. After performing the sum $S$ for each pentad of the year, the time series of $S$ was smoothed with a moving average of 3 points applied 50 times. In the next step the first derivative of $S(d S / d t)$ was calculatedto identify the onset and demise of the rainy season of each year. Initially, $d S / d t$ has positive values and its first negative value $(d S / d t<0)$ defines the onset of the dry season, that is, the demise of the rainy season which started in the previous year. The derivative $d S / d t$ shows a sequence of negative values and when the signal changes to positive $(d S / d t>0)$ the onset of the rainy season occurs [5]. This methodology was applied in the SAM subdomain (Figure 1) to identify the onset and demise of the SAM in the present and future climates.

\section{Results}

3.1. Present Climate Simulations. In summer (Figures 2(a)$2(\mathrm{~d})$ ), the average air temperature is about $26^{\circ} \mathrm{C}$ throughout most of SA, but three cooler regions are also noticed: southernmost SA, over the Andes, and southeastern Brazil. The lower temperatures in this last region are due to the high topography of Serra do Mar and Serra da Mantiqueira. NCEP reanalysis (Figure 2(c)), in general, is colder than CRU analysis (Figure 2(d)). The simulated temperatures (from RegHad and RegECHAM) are closer to the CRU analysis, except for the cold (warm) bias over Amazon region (northern Argentina). The northern Argentina warm bias is a common problem of the RegCM previous versions [16,31] and of other RCMs [13] during summer; however, it disappears in winter (Figures 2(e)-2(h)). In this season the simulations are also colder compared to CRU in northern Brazil. It is noteworthy that in summer and winter both simulations reproduce the lowest temperatures over the eastern sector of southeastern Brazil.

For air temperature annual cycle of the five subdomains shown in Figure 1, AMZ (Figure 3(a)) is the one with the lowest monthly variability, while in the SO (Figure 3(d)) 


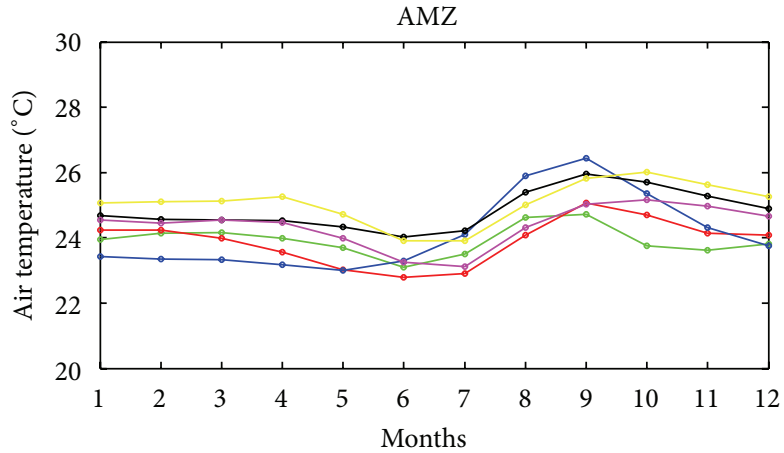

(a)

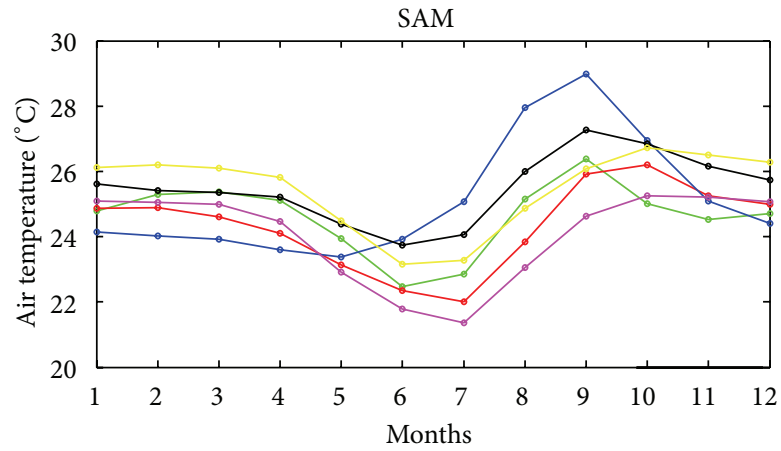

(b)

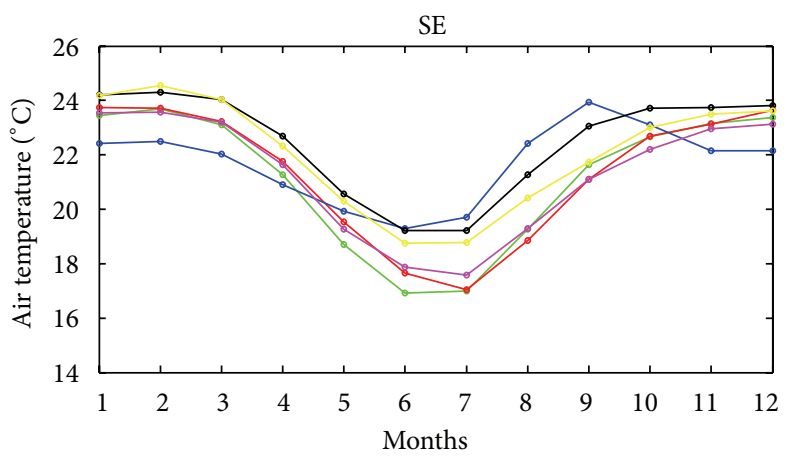

(c)

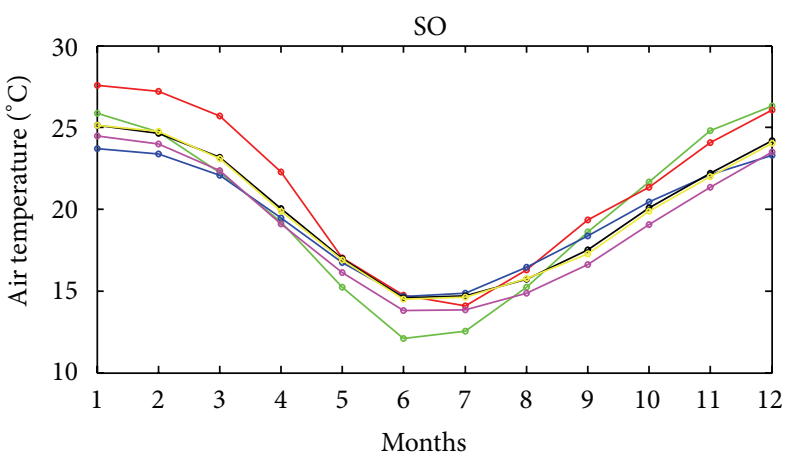

$\begin{array}{ll}\rightarrow \text { RegHad } & \rightarrow \text { ERA-40 } \\ \rightarrow \text { RegECHAM } & \because \text { CRU } \\ \rightarrow \text { NCEP1 } & \rightarrow \text { U. Delaware }\end{array}$

(d)

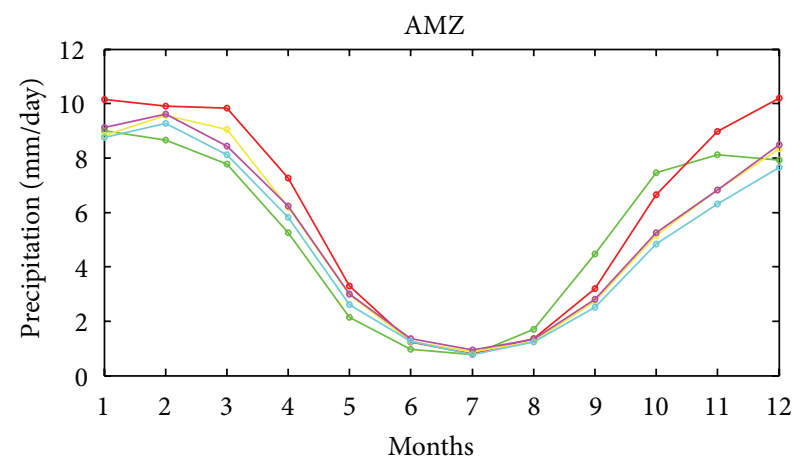

(f)

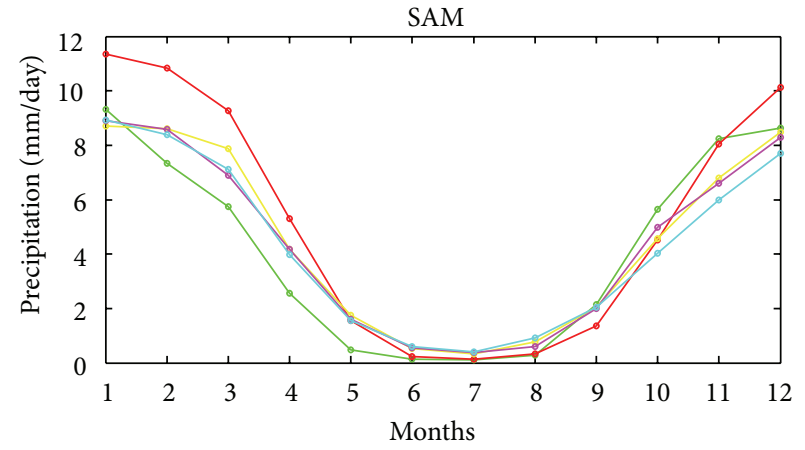

(g)

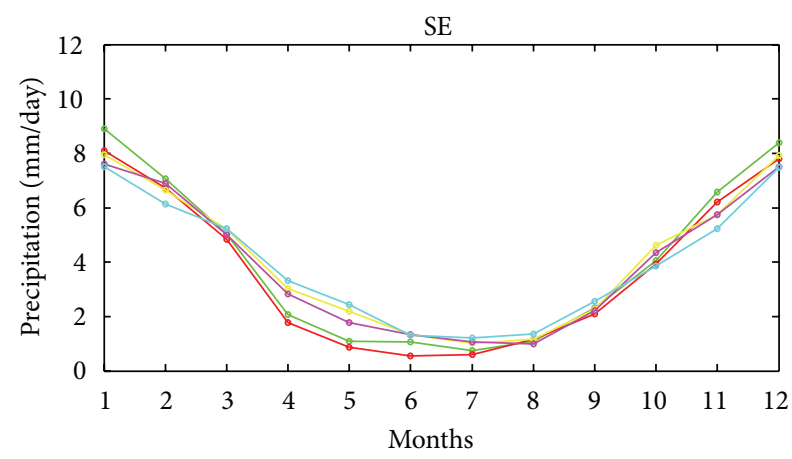

(h)

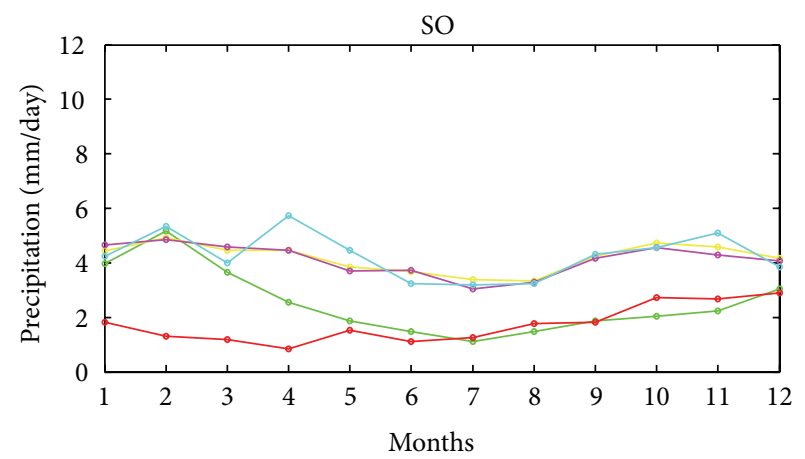

$\because$ U. Delaware

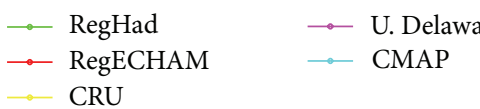

(i)

Figure 3: Continued. 


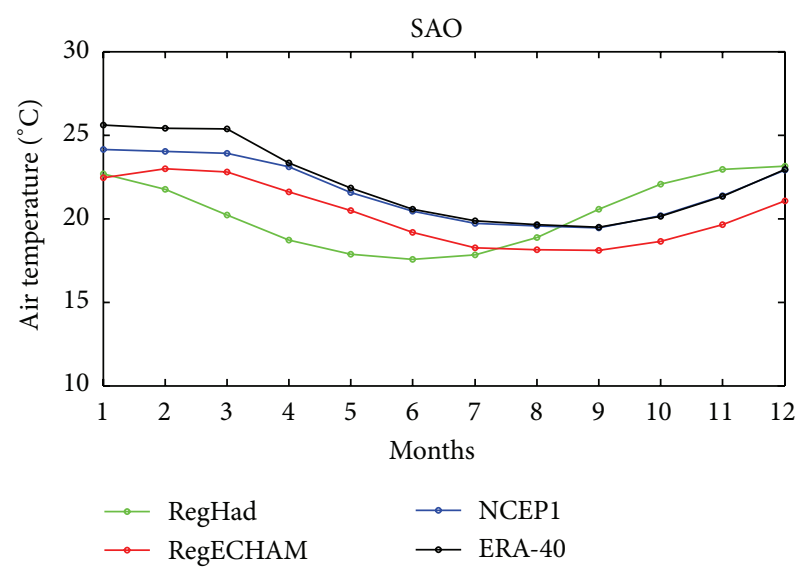

(e)

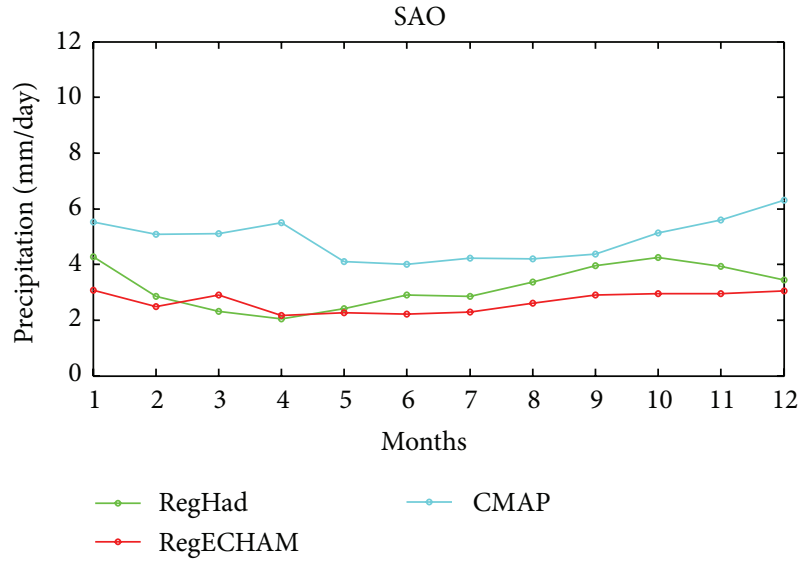

(j)

Figure 3: Annual cycle of air temperature $\left({ }^{\circ} \mathrm{C}\right.$; left) and precipitation ( $\mathrm{mm} \mathrm{day}^{-1}$; right), from 1960 to 1990 (except CMAP: 1979-1990), in the five subdomains of South America shown in Figure 1: AMZ, SAM, SE, SO, and SAO. In the panels the green line represents the RegHad, the red line RegECHAM, the blue line NCEP, the black line ERA-40, the yellow line CRU, the pink line University of Delaware, and the cyan line CMAP.

the variability is the largest. In AMZ (Figure 3(a)), RegHad and RegECHAM simulate values that are closer to UDEL analysis, and they are able to reproduce the observed annual cycle pattern. This last feature is also obtained for SAM region (Figure 3(b)). In this region RegHad is slightly colder and warmer than CRU and UDEL, respectively. On the other hand, RegECHAM is similar to UDEL from November to May. In SE (Figure 3(c)) simulated values of air temperature are almost the same as from UDEL analysis. In both, SAM and SE, NCEP and ERA40 reanalyses overestimate the air temperature from June to December compared to CRU and UDEL, while both RegHad and RegECHAM produce results similar to these analyses. In SO (Figure 3(d)), RegECHAM overestimates the air temperature from September to May and in the remaining months its values are similar to other analyses. In this region, RegHad presents smaller biases from January to April, and the bias changes from negative for the period of May-July to positive for September-December. In the subdomain over the SAO (Figure 3(e)), NCEP and ERA40 reanalyses present the same air temperature values and annual cycle, where the minimum occurs between August and September. RegECHAM represents this pattern of the air temperature annual cycle recorded in the reanalyses, but it is about $2^{\circ} \mathrm{C}$ colder. RegHad differs from RegECHAM and the reanalyses due to an increase of temperatures from August to November and decrease in the other months. Furthermore, it is also colder than the reanalyses from January to August.

The main feature of the precipitation in summer (Figures $4(\mathrm{c})$ and $4(\mathrm{~d})$ ) over SA is the maximum rainfall which extends in a northwest-southeast band from Amazon to southeastern Brazil and over the SAO. This band characterizes the South Atlantic Convergence Zone (SACZ; [47, 49, 50]). In this season, RegHad (Figure 4(a)) has a precipitation spatial pattern that resembles CMAP and CRU (Figures 4(c) and $4(\mathrm{~d}))$. However, the simulation shifts the southeastern portion of the continental SACZ to south (between Paraná and São Paulo states). On the other hand, RegECHAM
(Figure 4(b)) does not simulate SACZ but presents a large area with maximum precipitation over central Brazil. Moreover, it simulates erroneously high values of precipitation in northeastern Brazil, which is not evident in the analyses (Figures 4(c) and 4(d)) and in the RegHad (Figure 4(a)). RegHad displaces the SACZ oceanic branch to north while RegECHAM practically does not simulate this climate feature compared to CMAP. During winter (Figures 4(e)-4(h)), the precipitation reaches its minimum in almost all SA, except in southern Brazil, where precipitation values are similar to summer, and in the northernmost region of the continent. The RegCM3 simulations (Figures 4(e) and 4(f)) reproduce the spatial pattern of precipitation, but they underestimate the values in $\sim 2 \mathrm{~mm}$ day $^{-1}$ over southern Brazil and they are slightly wetter on the southern Amazon. Over the Atlantic Ocean near the southern Brazilian coast, around $30^{\circ}$ to $40^{\circ} \mathrm{S}$, precipitation is underestimated in the simulations. This fact can be associated with lower extratropical cyclones occurrence in the simulations using RegCM $[16,51]$.

We also carried out a detailed analysis of the precipitation annual cycle in the five subdomains of Figure 1. AMZ, SAM, and SE (Figures 3(f)-3(h)) show higher precipitation in summer and lower in winter which is characteristic of a monsoon regime $[4,41]$. Both simulations captured the pattern of the annual cycle in these subdomains. In AMZ (Figure 3(f)), the simulations have values similar to those of the analyses between June and August, but from February to May, the RegHad underestimates the precipitation, while the RegECHAM overestimates it. This last also has higher overestimation than RegHad in November and December. In SAM (Figure 3(g)), RegHad underestimates the precipitation from February to June, shows similar values to the analyses from July to September, and overestimates it from October to November. On the other hand, RegECHAM is similar to the analyses from May to September and wetter from December to April. Seth et al. [11] also obtained an overestimation of precipitation in this region in summer 


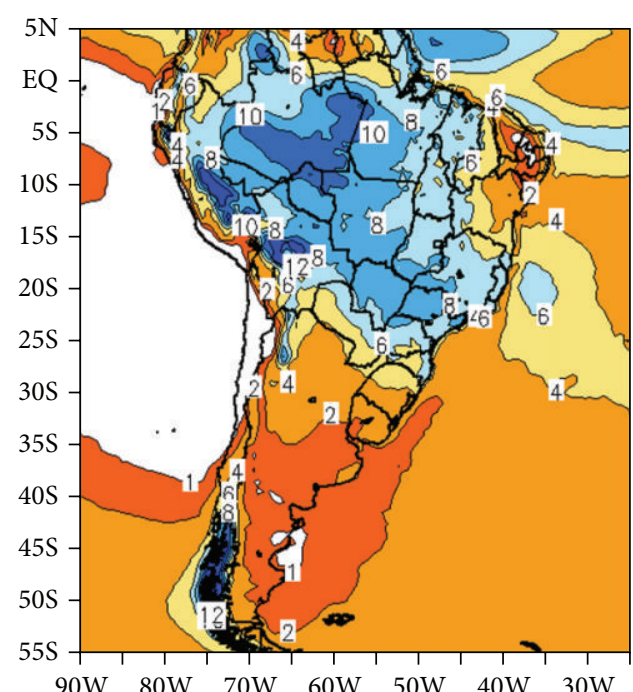

(a) RegHad, summer (1960-1990)

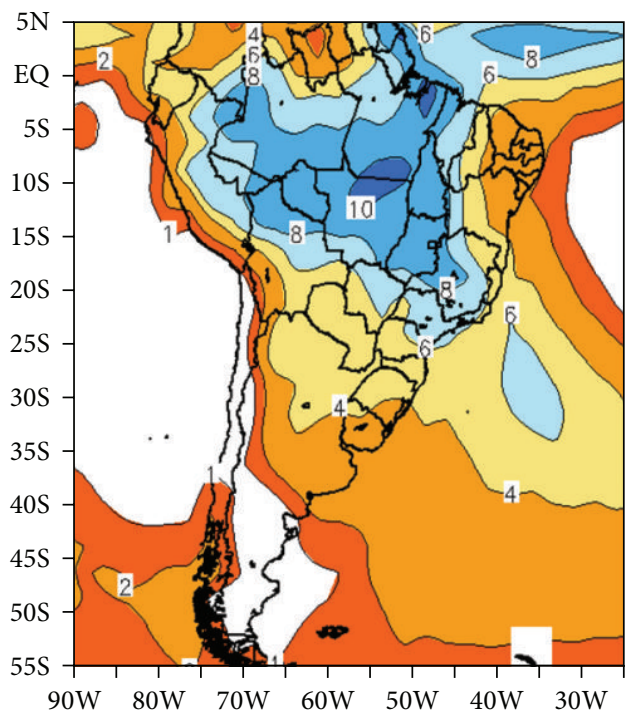

(c) CMAP, summer (1979-1990)

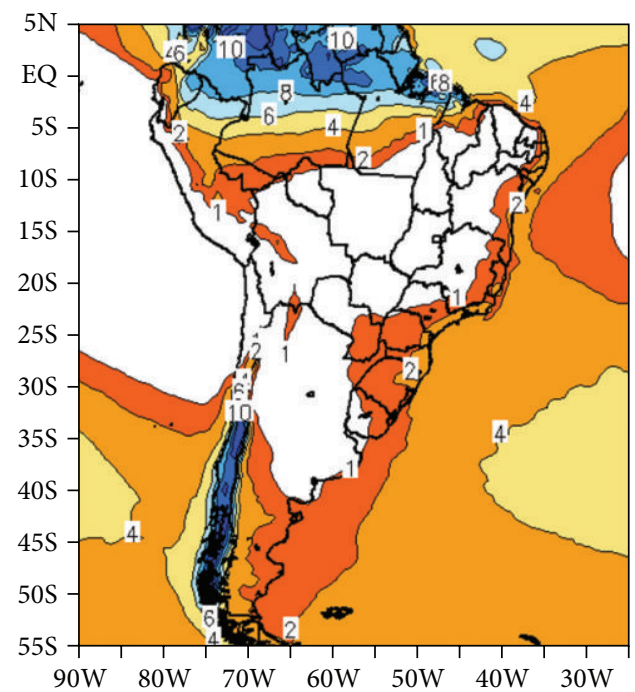

(e) RegHad, winter (1960-1990)

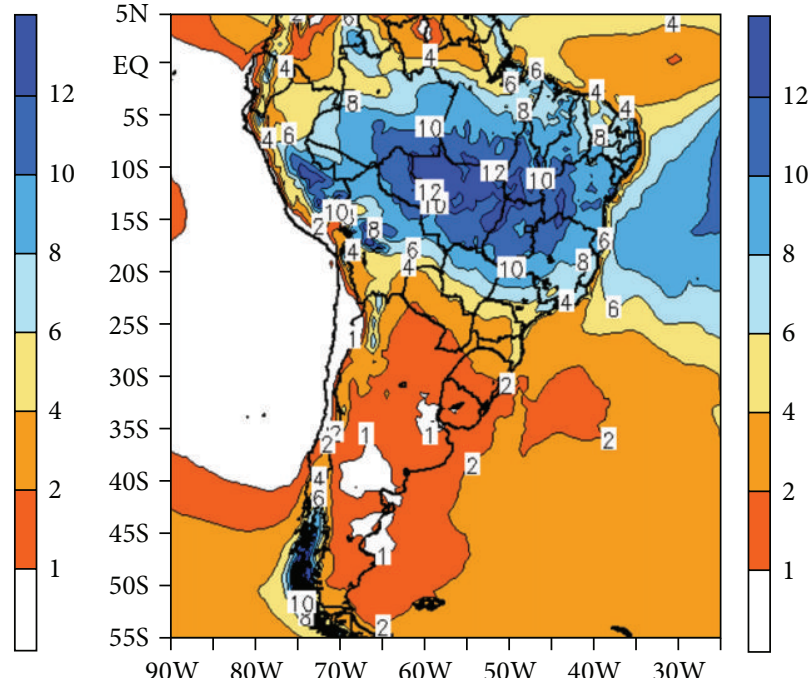

(b) RegECHAM, summer (1960-1990)
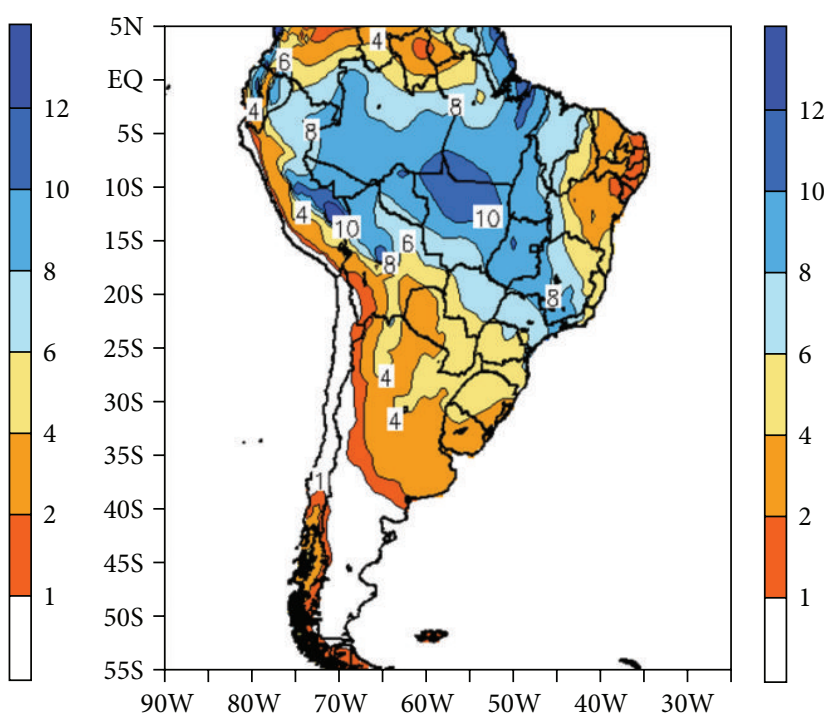

(d) CRU, summer (1960-1990)
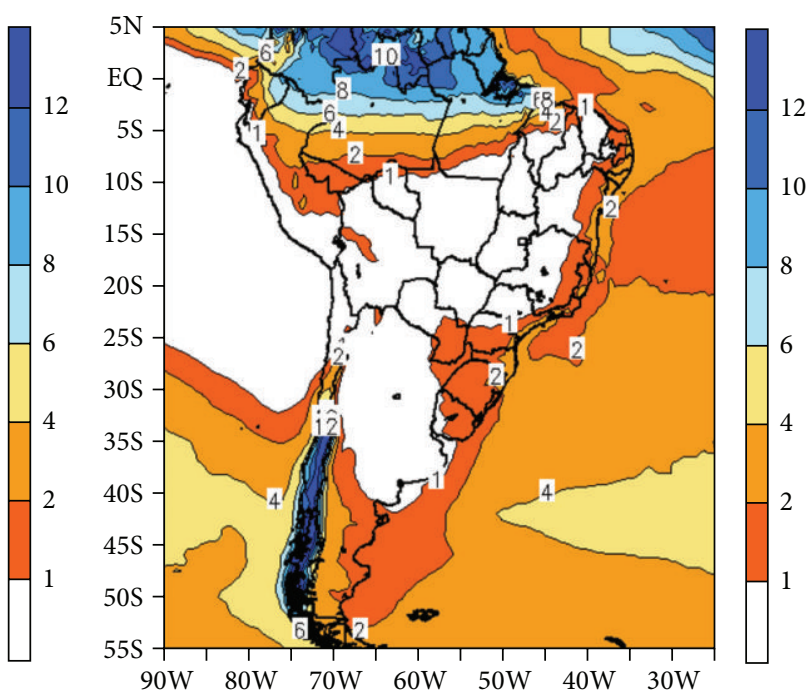

(f) RegECHAM, winter (1960-1990)

Figure 4: Continued. 


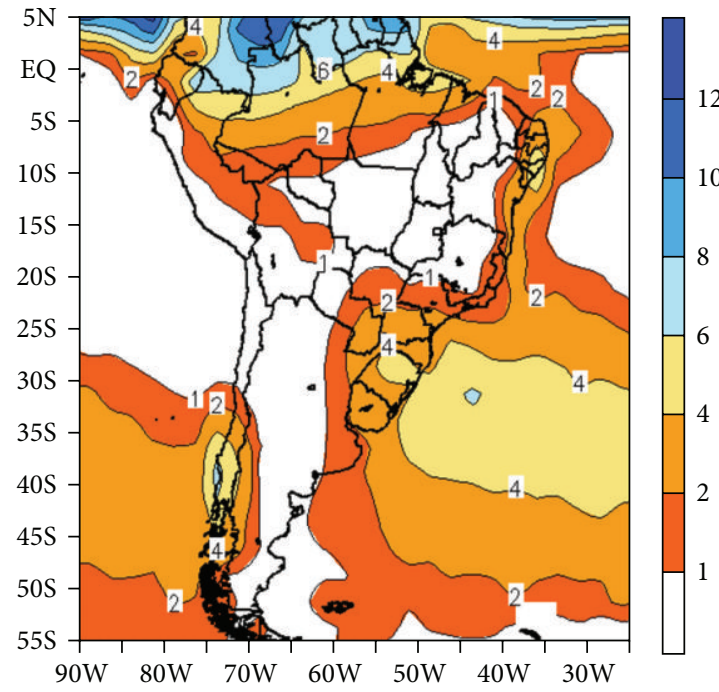

(g) CMAP, winter (1979-1990)

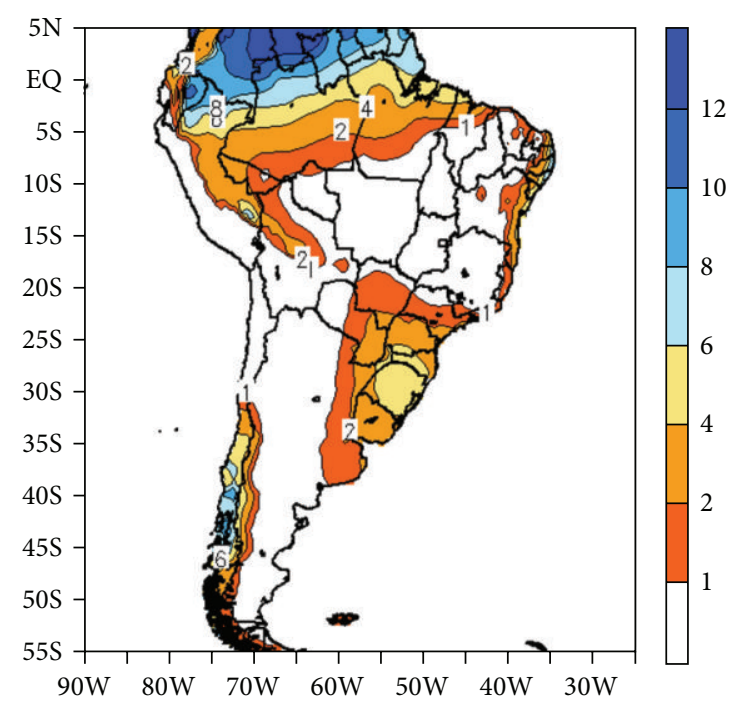

(h) CRU, winter (1960-1990)

FIGURE 4: Mean precipitation $\left(\mathrm{mm} \mathrm{day}^{-1}\right)$ in $((\mathrm{a})-(\mathrm{d}))$ summer and ((e)-(h)) winter for the present (1960-1990) climate from RegHad, RegECHAM, CMAP, and CRU.

when they nested RegCM3 to ECHAM4.5 simulations. In SE (Figure 3(h)), both simulations show values similar to the analyses, except the small underestimates from April to June. In SO (Figure 3(i)), the analyses show a monthly precipitation with little variation throughout the year, although there is a slight minimum in winter. The simulations fail to reproduce the observed annual cycle and also underestimate the precipitation, except RegHad from January to March when it shows values near to the observations. Over the SAO (Figure 3(j)) the monthly precipitation behavior is similar to SO. Although both simulations underestimate the precipitation values, RegECHAM simulates the annual cycle phase more similarly to CMAP than RegHad.

Based on the validation of air temperature and precipitation in the period from 1960 to 1990 , it is noticed that the RegCM3 can reproduce the main features of SA climate, that is, the seasonal spatial pattern of air temperature and precipitation as well as the annual cycle of these variables in different regions of the continent. Therefore, we can use the model in studies for future climate.

\subsection{Future Climate Projections}

3.2.1. Period from 2010 to 2040. The spatial pattern of the air temperature average projected for 2010 to 2040 (Figure 5) shows that in most part of SA the air temperature will increase by about $2^{\circ} \mathrm{C}$ in all seasons. In summer, RegHad (Figure 5(a)) projects a temperature increase of about $2^{\circ} \mathrm{C}$ throughout $\mathrm{SA}$, except in southern Brazil, Uruguay, Paraguay, and northern Argentina where the warming is about $1^{\circ} \mathrm{C}$. For this same area, RegECHAM (Figure 5(b)) projects an increase of about $2^{\circ} \mathrm{C}$ as well as in northern Brazil. In this projection, the temperature increase is less pronounced $\left(\sim 1^{\circ} \mathrm{C}\right)$ in the westcentral and northeastern Brazil and in the southernmost SA compared to RegHad. In autumn (figure not shown), RegHad simulates a small region with temperatures above $2^{\circ} \mathrm{C}$ on Tocantins State and northeastern Mato Grosso State; however, this warm area extends westward in winter (Figure 5(c)), covering a large part of the west-central Brazil. In both autumn (figure not shown) and winter (Figure 5(d)), the temperature increase projected by RegECHAM migrates southeastward compared with summer pattern (Figure 5(b)). In spring, the RegHad (figure not shown) projects a temperature increase of about $2^{\circ} \mathrm{C}$ throughout the SA, except in the east of the northeastern and west-central regions of Brazil, where temperatures exceed $2^{\circ} \mathrm{C}$. In RegECHAM (figure not shown), the temperature increase is restricted to a maximum of $2^{\circ} \mathrm{C}$.

Regarding precipitation from 2010 to 2040 (Figure 6), the two simulations project less precipitation over northern SA throughout the year compared to present. In summer (Figures 6(a) and 6(b)), the precipitation decrease (reaching $1.5 \mathrm{~mm} \mathrm{day}^{-1}$ ) extends from the southern Amazon and Pará States to the north of SA in both simulations. They also show an area with precipitation increase in the northcentral Argentina. In this season, RegECHAM differs from RegHad by showing a wet large area among the west-central Brazil, western Bolivia, and northern Paraguay, which is not simulated by RegHad. In autumn, RegHad (figures not shown) simulates a precipitation deficit $\left(\sim 1.5 \mathrm{~mm}\right.$ day $\left.^{-1}\right)$ in northern Brazil, while RegECHAM (figures not shown) shows a deficit displaced far north SA. In winter, both simulations (Figures 6(c) and 6(d)) project a precipitation decrease of about $1.5 \mathrm{~mm} \mathrm{day}^{-1}$ in the northern SA and center of Chile. In spring (figures not shown), RegHad shows a precipitation decrease $\left(\sim 1.5 \mathrm{~mm} \mathrm{day}^{-1}\right)$ in a large area of SA northward $20^{\circ} \mathrm{S}$ (except in the east region of northeastern Brazil) and an increase in Paraguay. These projections occur in a smaller area in RegECHAM (figures not shown). 


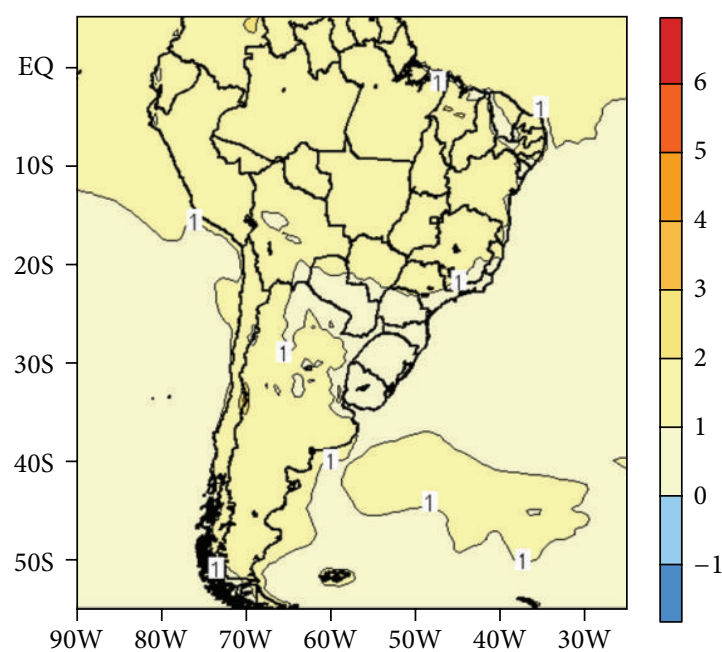

(a) RegHad (summer)

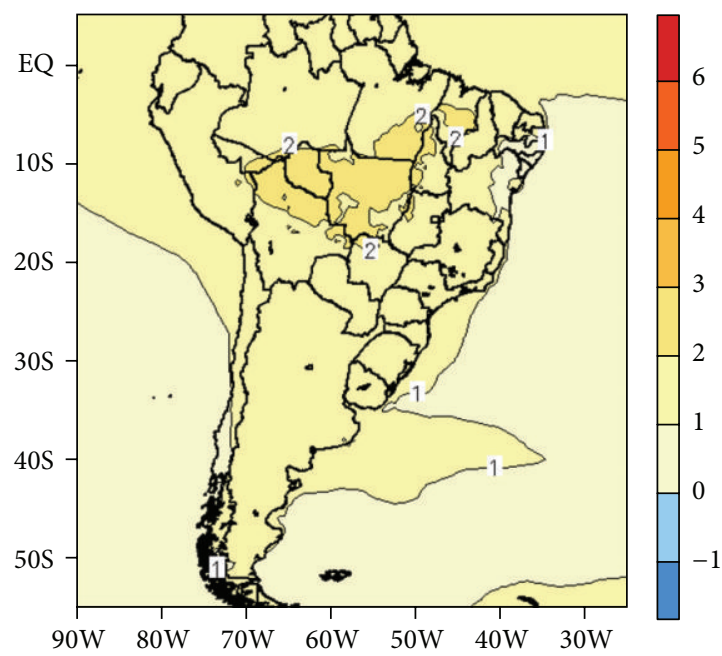

(c) RegHad (winter)

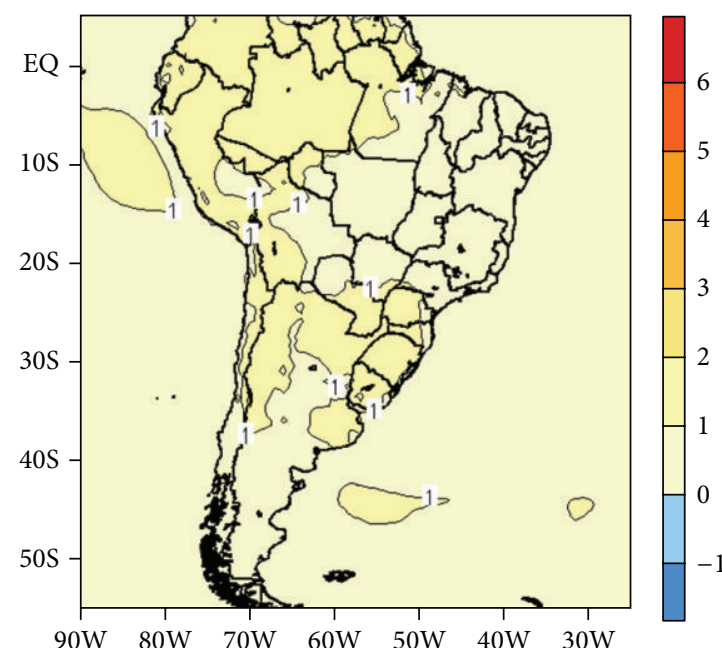

(b) RegECHAM (summer)

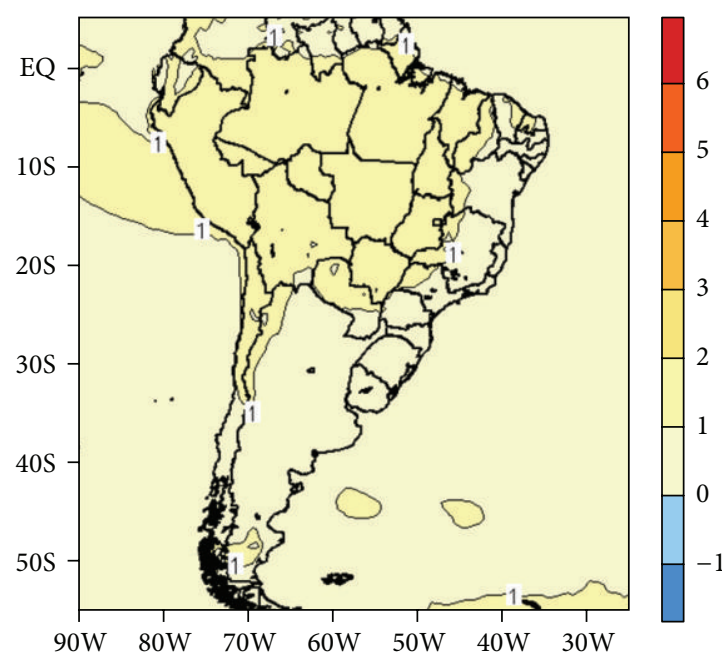

(d) RegECHAM (winter)

Figure 5: Projected mean change in the near-future climate (2010-2040 minus 1961-1990) of air temperature $\left({ }^{\circ} \mathrm{C}\right)$ simulated by RegHad (left column) and RegECHAM (right column) for summer (top) and winter (bottom).

The projected changes in low level $(850 \mathrm{hPa})$ winds in all seasons and in both simulations suggest that the dryer conditions over northern SA are associated with the weakening of the northeast trades over tropical Atlantic Ocean (Figure 6). A similar result was found by Marengo et al. [17]. On the other hand, over Amazon State the trade winds present intensification and in RegECHAM theses winds contribute to the intensification of the low level jet to east of Andes and the precipitation increase over central SA. In the subtropical Atlantic Ocean, RegHad and RegECHAM show different wind changes in summer (winter): while RegHad projects weakening (strengthening) of the subtropical Atlantic high near the Brazilian coast (Figure 6(a)), RegECHAM projects strengthening (weakening) of this system (Figure 6(b)).

3.2.2. Period from 2070 to 2100. During the period from 2010 to 2040 an air temperature increase up to $2^{\circ} \mathrm{C}$ over
SA by RegECHAM and $3^{\circ} \mathrm{C}$ by RegHad is projected; in the period from 2070 to 2100 , this increase is almost tripled in both simulations. Again, the higher values are projected by RegHad (Figure 7). In summer (2070-2100), RegHad (Figure $7(\mathrm{a})$ ) shows a temperature increase of more than $6^{\circ} \mathrm{C}$ from southern Amazon to northern SA which is not simulated by RegECHAM (Figure 7(b)). The RegHad projections show similar results from [15] when HadRM3P was nested in RegCM3 considering A2 scenario. But these simulations overestimate those from [16] considering the period from 2071 to 2085 and also the A2 scenario. In autumn (figures not shown), while RegECHAM projects a temperature increase of $3-4^{\circ} \mathrm{C}$ in almost all Brazilian territory, RegHad simulates a maximum of more than $6^{\circ} \mathrm{C}$ between the northern and northeastern Brazil. In the region among Paraguay, northern Argentina, Uruguay, and southern Brazil, RegHad is about $1^{\circ} \mathrm{C}$ cooler than RegECHAM. In winter, the region between west-central and northern Brazil is the one with the highest 


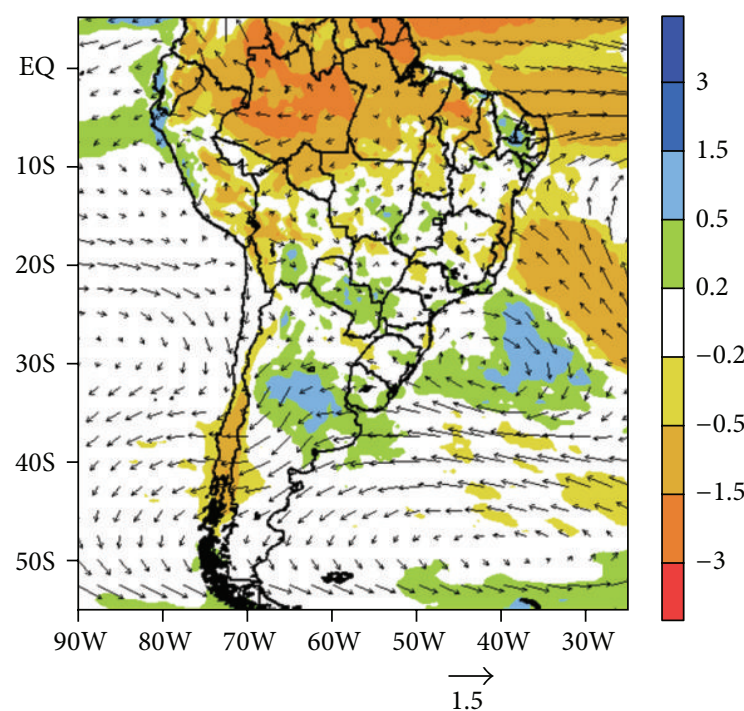

(a) RegHad (summer)

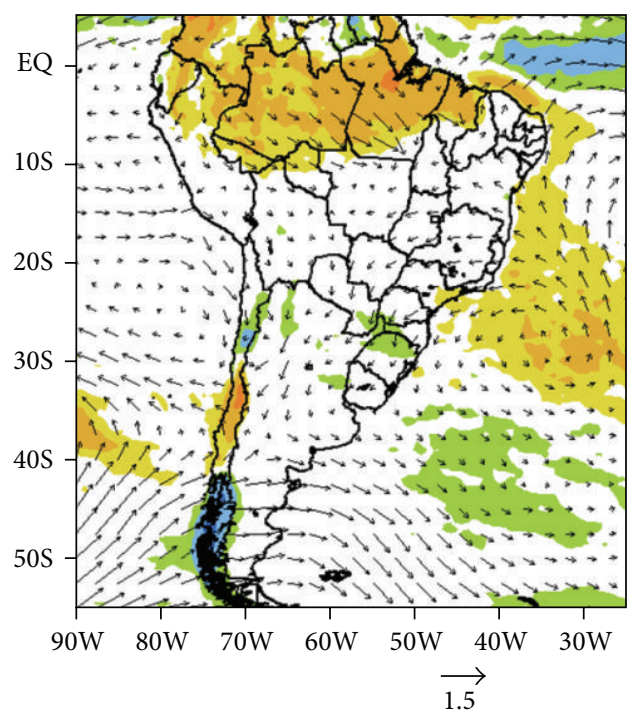

(c) RegHad (winter)

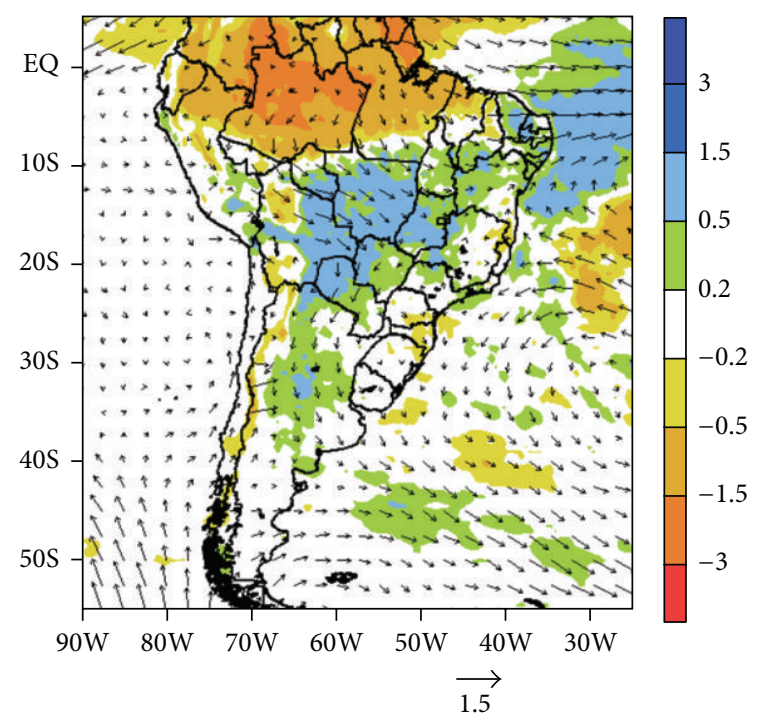

(b) RegECHAM (summer)

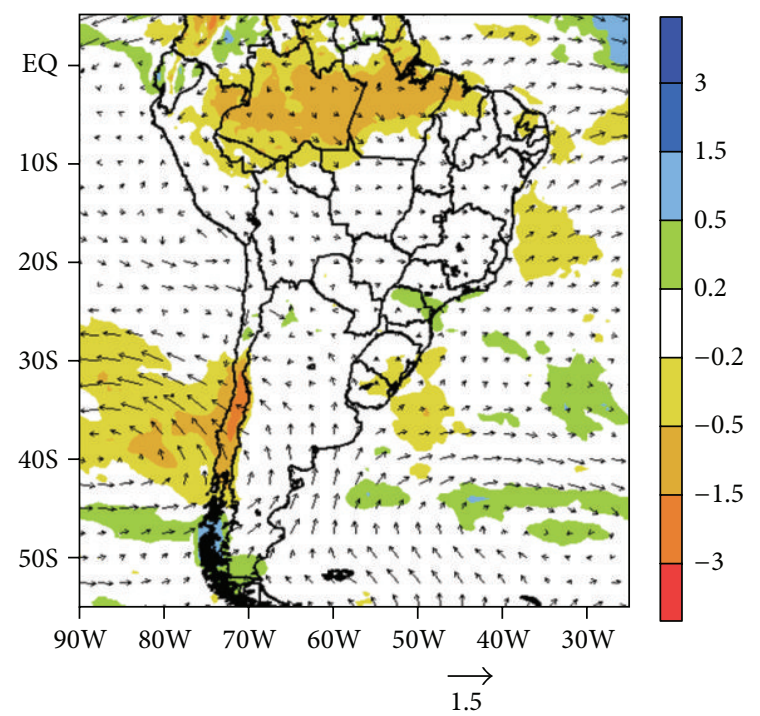

(d) RegECHAM (winter)

FIGURE 6: Projected mean change in the near-future climate (2010-2040 minus 1961-1990) of precipitation $\left(\mathrm{mm} \mathrm{day}^{-1}\right)$ and $850 \mathrm{hPa}^{-\mathrm{ind}}$ $\left(\mathrm{m} \mathrm{s}^{-1}\right.$; arrows) simulated by RegHad (left column) and RegECHAM (right column) for summer (top) and winter (bottom).

air temperature increase in RegHad (Figure $7(\mathrm{c})$ ). In this area, the temperature increases to more than $6^{\circ} \mathrm{C}$ between 2070 and 2100. RegECHAM (Figure 7(d)) also simulates a large area with air temperature increase but with lower values than that of RegHad (maximum between $5^{\circ}$ and $6^{\circ} \mathrm{C}$ ). In spring (figures not shown), RegECHAM (RegHad) projects a temperature increase lower (higher) than $6^{\circ} \mathrm{C}$ between northern and northeastern Brazil. It is interesting to highlight that in Argentina, in general, an air temperature increase of about $3^{\circ} \mathrm{C}$ is expected in all seasons and in both simulations.

The period from 2070 to 2100 also shows greater differences in seasonal precipitation in relation to the present climate (1960-1990) than the period from 2010 to 2040 . From 2070 to 2100 (Figure 8), in all seasons, a reduction is projected in precipitation between Amazon State and northern SA. This reduction is more pronounced in spring and summer in both simulations. In summer, RegHad (Figure 8(a)) projects a precipitation reduction higher than $3.0 \mathrm{~mm} \mathrm{day}^{-1}$ in the north-central SA while RegECHAM projection (Figure 8(b)) is between 1.5 and $3.0 \mathrm{~mm}^{-1}$ day $^{-1}$ and only in northern SA. Both simulations also indicate that the northeastern coast of Brazil is drier in the future. These results agree with the ensemble determined with three RCMs by [15]. The region formed by central-northern Argentina and Paraguay is wetter in both simulations than in the present $\left(\sim 1.5 \mathrm{~mm} \mathrm{day}^{-1}\right)$. This region with higher precipitation is also observed in global models ensemble from IPCC-AR4 and in several studies with RCMs as in $[16,19]$. In autumn (figures not show) and 


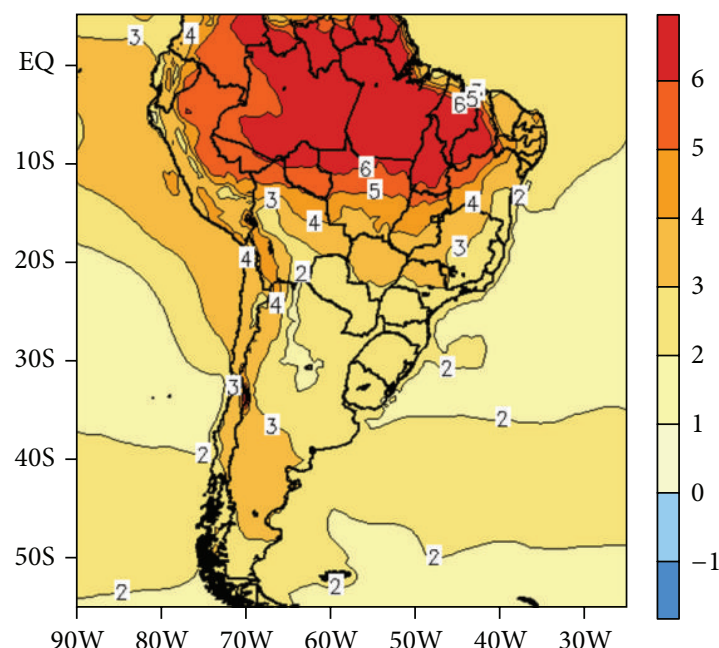

(a) RegHad (summer)

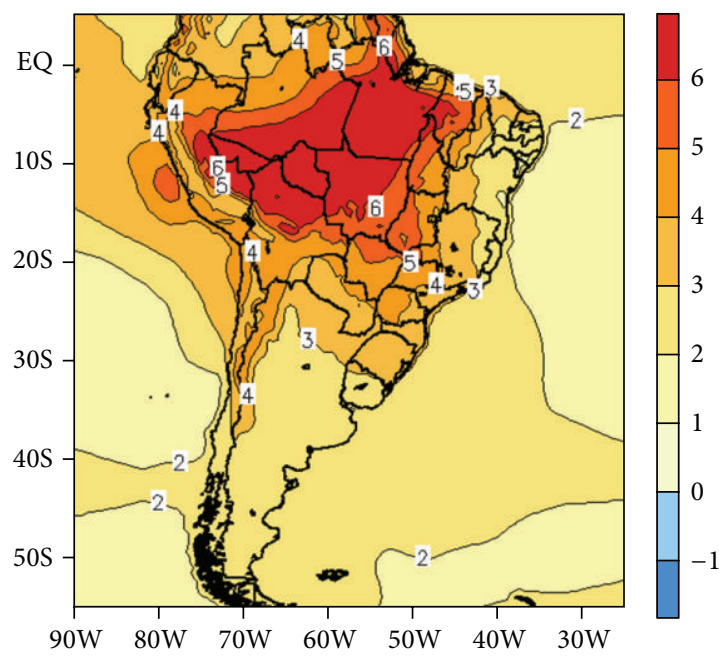

(c) RegHad (winter)

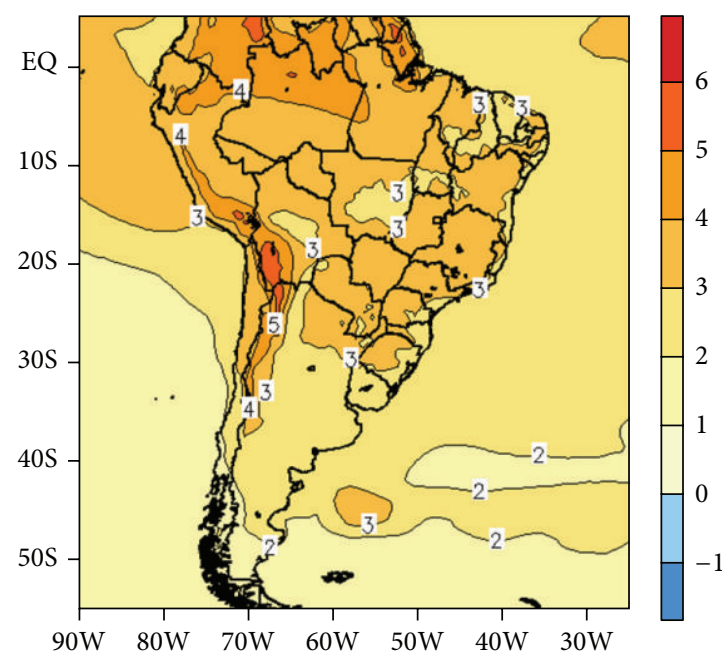

(b) RegECHAM (summer)

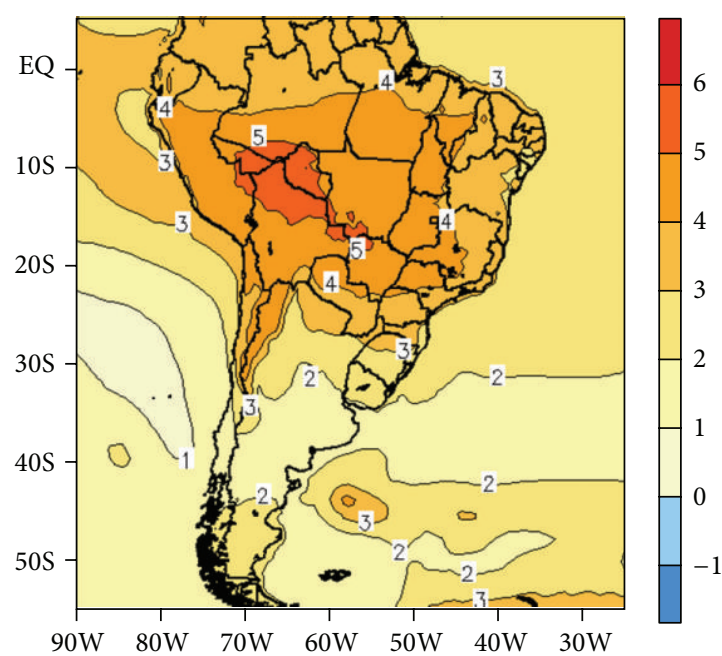

(d) RegECHAM (winter)

Figure 7: Similar to Figure 5, but in the far-future period (2070-2100 minus 1960-1990).

winter (Figures $8(\mathrm{c})$ and $8(\mathrm{~d})$ ), the differences in precipitation (positive and negative) in relation to the present climate are lower than in summer. But they increase again in spring (figures not show) in both RegHad and RegECHAM. Spring is the season with wetter conditions over the SESA with a projected precipitation increase higher than $3 \mathrm{~mm} \mathrm{day}^{-1}$.

The weakening projected in the northeast trades over tropical Atlantic Ocean in the far period is higher than in the near-future contributing to the increase in the rainfall negative bias over northern SA (Figure 8). In summer, RegECHAM (Figure 8(a)) projects a more intense low level jet to east of the Andes than RegHad (Figure 8(b)) and this jet can increase the precipitation over Bolivia and Paraguay. In winter, the subtropical Atlantic high is more intense in the far period only in RegHad. While the winds of the west sector of that high can contribute to the increase in the precipitation over southern Brazil in RegHad, in RegECHAM it is associated with the low level jet to east of the Andes.
3.3. Lifecycle of the South American Monsoon. We used the methodology from [5] to investigate the SAM lifecycle in the tropical SA $\left(10^{\circ}-20^{\circ} \mathrm{S}\right.$ and $\left.60^{\circ}-50^{\circ} \mathrm{W}\right)$. Initially we present a validation of the simulations in the present climate. Table 1 shows the SAM lifecycle obtained by [41] from 1979 to 1997, by [5] from 1979 to 2004, and in our simulations of the present climate (1960-1990). According to these authors, SAM onset in the tropics occurs between pentads 56 and 60, which represents October; the demise occurs between pentads 20 and 24, which represents April; and the length is about 38 pentads. In general, RegECHAM and RegHad simulate the SAM lifecycle similarly to the observations (Table 1 ). However, RegHad anticipates the onset and demise of the rainy season in three pentads compared to RegECHAM. But both simulations indicate the same SAM length (37 pentads). Regarding 2010 to 2040 future climate (Table 2), both RegHad and RegECHAM produce a delay of one pentad in the rainy season onset compared with the present climate and both 


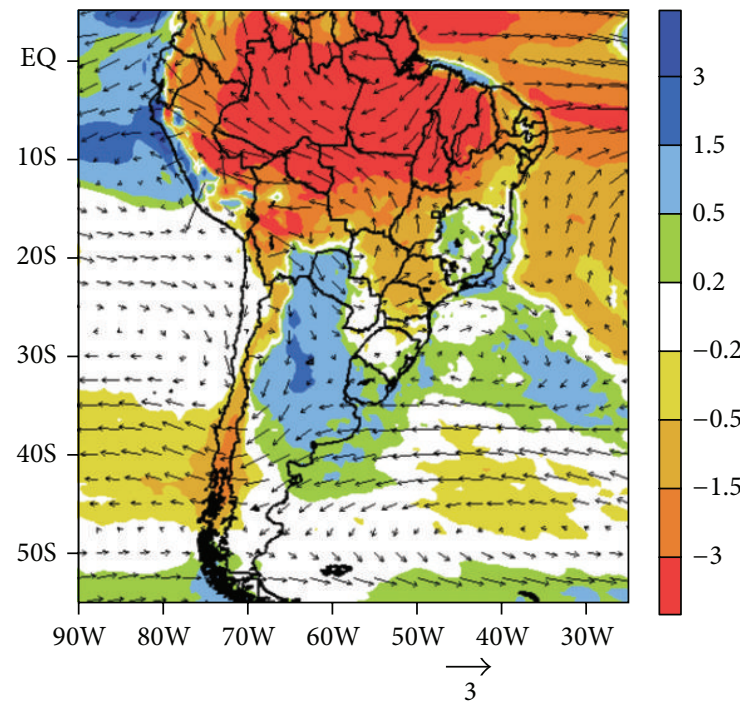

(a) RegHad (summer)

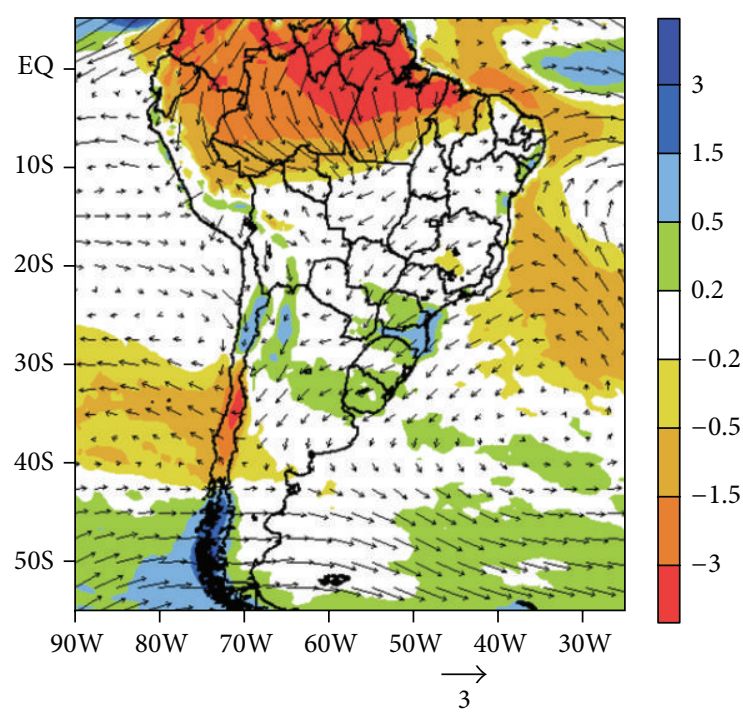

(c) RegHad (winter)

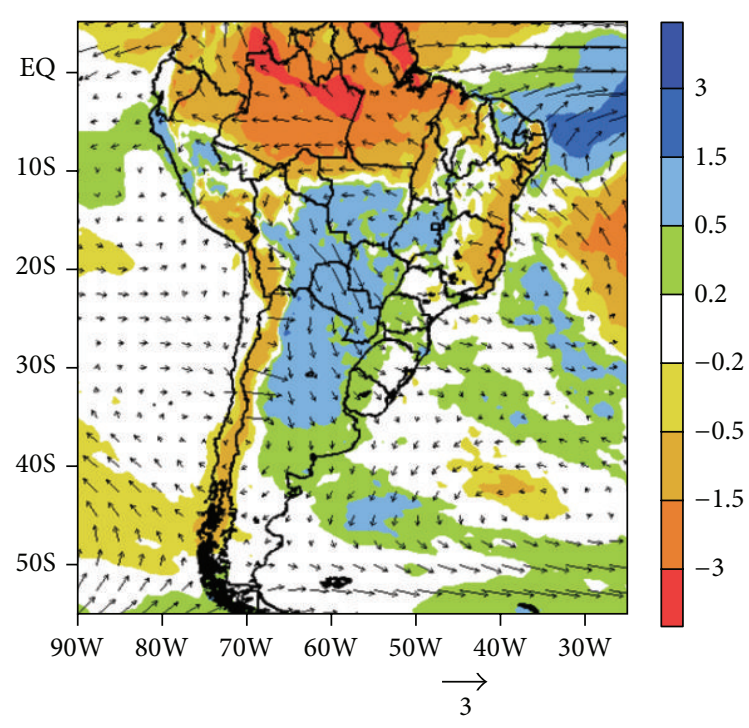

(b) RegECHAM (summer)

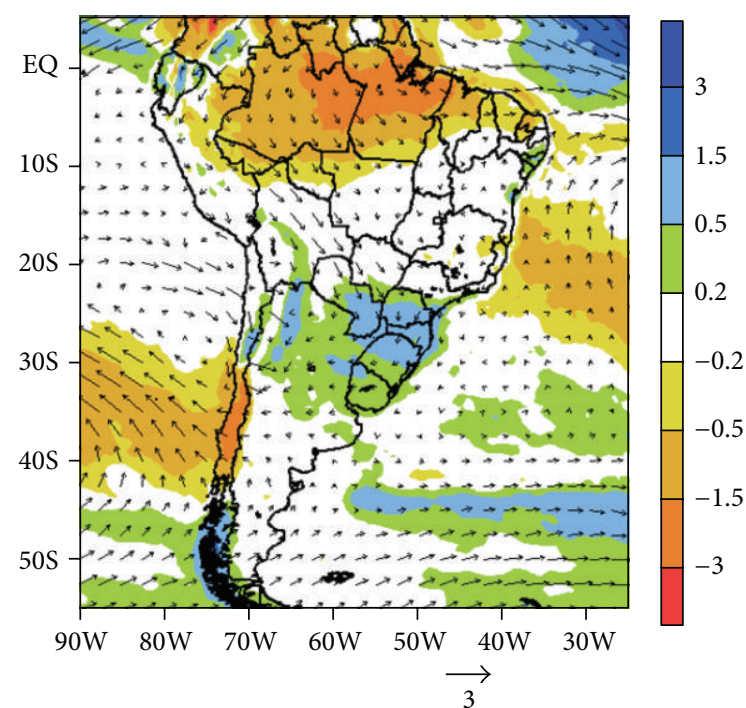

(d) RegECHAM (winter)

Figure 8: Similar to Figure 6, but in the far-future period (2070-2100 minus 1960-1990).

TABLE 1: Lifecycle of the South American monsoon in the present (1960-1990) climate (details are in the text).

\begin{tabular}{lcccc}
\hline & $\begin{array}{c}\text { Mean } \\
\text { and standard-deviation } \\
\text { Gan et al. }(2006)[41]\end{array}$ & $\begin{array}{c}\text { Median } \\
\text { Bombardi and Carvalho } \\
(2008)[5]\end{array}$ & $\begin{array}{c}\text { Mean } \\
\text { and standard-deviation } \\
\text { RegECHAM }\end{array}$ & $\begin{array}{c}\text { Mean } \\
\text { and standard-deviation } \\
\text { RegHad }\end{array}$ \\
\hline Onset & $58( \pm 3)$ & $56-60$ & $59( \pm 1.6)$ & $56( \pm 1.0)$ \\
Demise & $22( \pm 2)$ & $20-24$ & $22( \pm 1.4)$ & $19( \pm 2.5)$ \\
Length & 38 & $\sim 38$ & 37 & 37 \\
\hline
\end{tabular}

TABLE 2: Similar to Table 1 but in near- and far-future climates (mean and standard-deviation of the pentads).

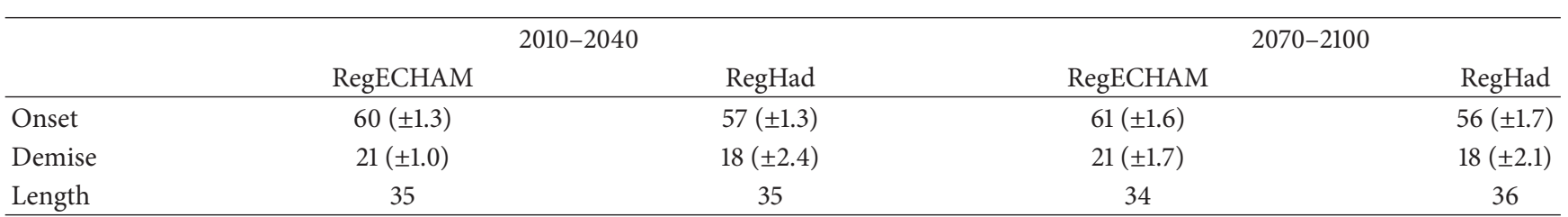


2070-2100

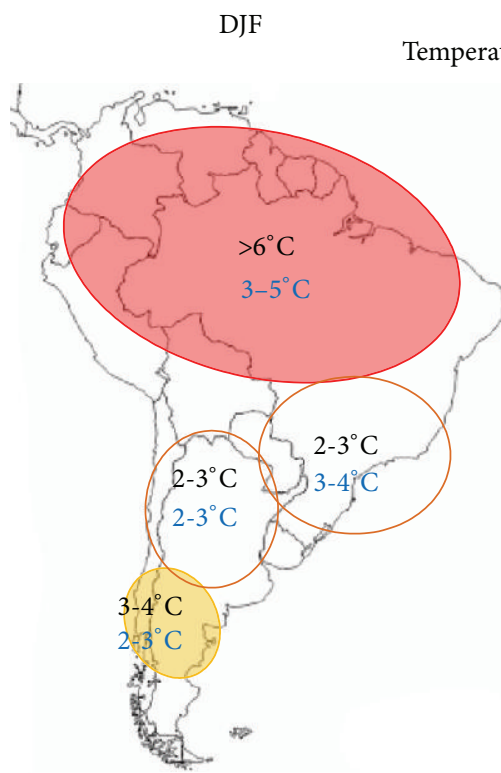

re change

JJA

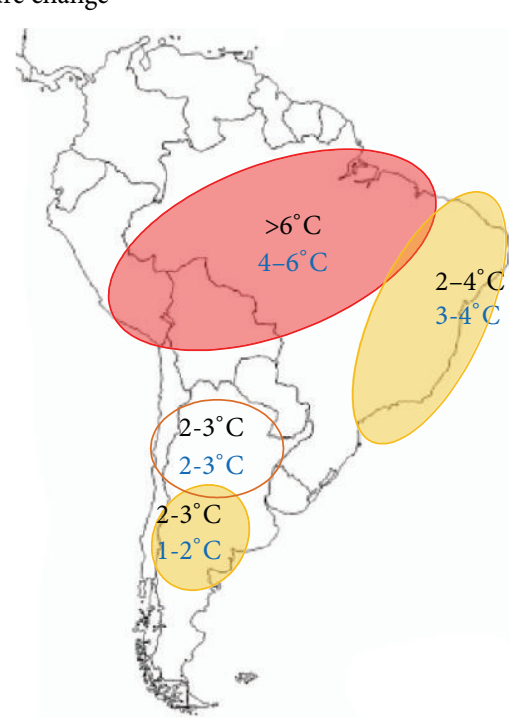

RegHad

RegHad

RegECHAM

RegECHAM

(a)

Precipitation change

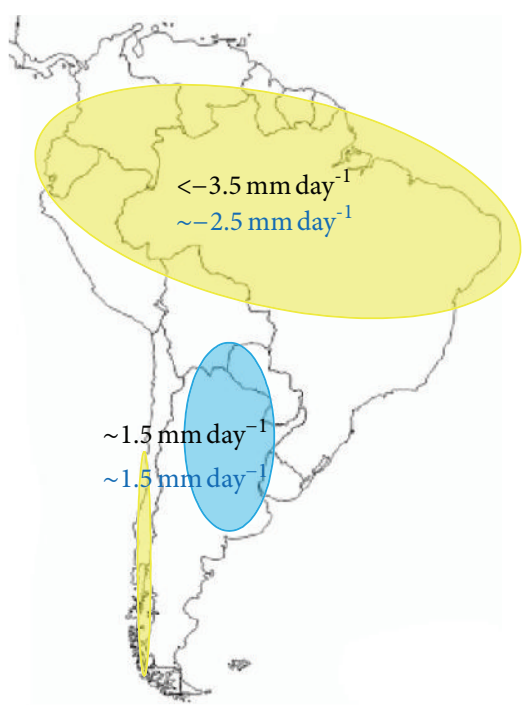

RegHad

RegECHAM

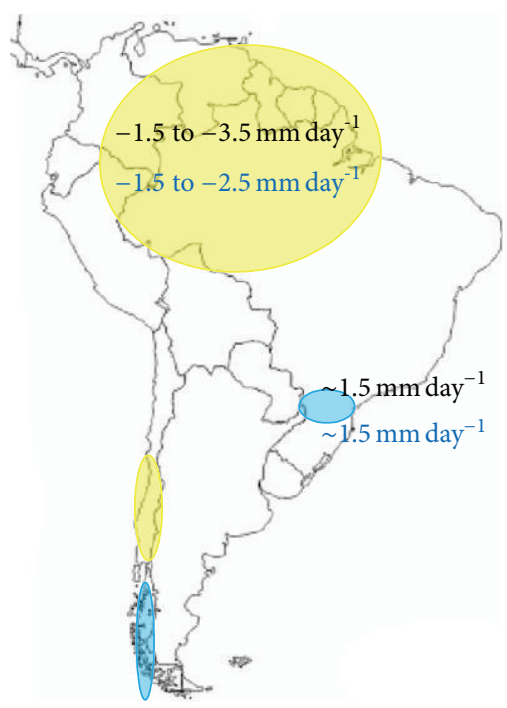

RegHad

RegECHAM

(b)

FIGURE 9: Projected changes of air temperature (upper panel) and precipitation (lower panel) by RegHad and RegECHAM for far-future (2070-2100 minus 1960-1990) climate for the A1B scenario from IPCC. Values in black (blue) represent RegHad (RegECHAM).

anticipate its demise, also by one pentad. Therefore, the length of the rainy season would be reduced by two pentads in 2010-2040. For the period from 2070 to 2100, RegECHAM delays the rainy season onset in two pentads and anticipates the demise in a pentad, which makes the length of the rainy season (34 pentads) lower than that for 2010-2040 (35 pentads). This result can be associated with the negative bias of precipitation in autumn and spring in SAM region (figures not shown). Differently from RegECHAM, RegHad projects for the far-future period conditions more similar to present 
climate than for 2010 to 2040 (Table 2). For example, the SAM onset for the far future (2070-2100) occurs in the pentad 56 as observed in the present climate, while its demise is only one pentad earlier than in the present climate.

\section{Conclusions}

In this study, initially, two present climate simulations (19601990) in SA carried out with RegCM3 nested in HadCM3 and ECHAM5 outputs were validated. Both simulations overestimated the air temperature in the northern Argentina and underestimated it in the Amazon. Emphasis was given to the good representation of the air temperature in the region of elevated topography in the east region of southeastern Brazil. Regarding precipitation, when RegCM3 is nested to HadCM3, continental SACZ is shifted south (between the Paraná and São Paulo States) and, when it is nested to ECHAM5, SACZ is not well represented, since the maximum rainfall is concentrated in the central and northeastern Brazil. The subdomains analysis showed that RegCM3, in general, simulates the phase and intensity of the annual air temperature and precipitation cycle in a similar way to the observations (CRU and UDEL). Therefore, these results indicate that RegCM3 is able to represent the climatic features of SA and can be employed for future climate studies. Then, SA climate in AlB scenario from IPCC was simulated by RegCM3 nested in HadCM3 and ECHAM5 projections in two future periods (2010-2040 and 2070-2100).

For the future, RegCM3 projects, in all the seasons, an air temperature increase throughout SA. From 2010 to 2040 the air temperature can increase by about $2^{\circ} \mathrm{C}$ but this value is higher from 2070 to 2100 . In this period, air temperature difference of the north-central Brazil may exceed $4^{\circ} \mathrm{C}$ in RegECHAM and $6^{\circ} \mathrm{C}$ in RegHad. The warmer conditions obtained in RegHad are associated with drier conditions of this simulations. A summary of the air temperature and precipitation changes projected to SA in the period from 2070 to 2100 is shown schematically in Figure 9. Regarding precipitation, from 2010 to 2040, both simulations project dry conditions in all seasons over northern SA. This pattern is intensified for 2070-2100 and extended to central SA in RegHad. Moreover, in the far-future period, both models project an increase of precipitation over SESA mainly in spring and summer. The air temperature and precipitation projections for 2070-2100 agree with the summary of several works analyzed by [14] and with other results from the literature (Marengo et al. [15], Marengo et al., [17], and Krüger et al. [16]). Moreover, as explained by Marengo et al. [17], the decrease in precipitation in the future scenarios over northern SA can be associated with the weakening of the trade winds in the tropical Atlantic. The trade winds transport humidity from the equatorial Atlantic to the Amazon. These low-level winds are then blocked by the Andes and deflected to southeast, advecting moisture to SESA. The weakening of this circulation would thus imply in less humidity transport to the subtropics of SA and in a rainfall decrease.

RegHad and RegECHAM simulate the SAM lifecycle in the present climate similar to the observations; that is, the rainy season onset in the SA tropics occurs between pentad 56 (RegHad) and 59 (RegECHAM) and the demise between pentad 19 (RegHad) and 22 (RegECHAM). From 2010 to 2040 , the two simulations project a delay of a pentad in the rainy season onset which leads to a small reduction in its lifetime. From 2070 to 2100 there is no agreement between the two simulations. While RegECHAM simulates a decrease of two pentads in the lifetime of the rainy season, RegHad indicates similar conditions to the present climate. It is important to highlight that the similarity between the two simulations in the 2010-2040 period may be a coincidence since in the far-future they disagree.

\section{Conflict of Interests}

The authors declare that there is no conflict of interests regarding the publication of this paper.

\section{Acknowledgments}

The authors thank the International Centre for Theoretical Physics (ICTP) for providing RegCM3 model; NCEP and ECMWF for reanalysis; CRU and the University of Delaware for the precipitation and air temperature analysis and CPC for observational analyses. This research was funded by CNPq (307202/2011-9), FAPESP (2011/51016-9), FAPEMIG (APQ-00251-11) and CAPES. The authors also received funding from the European Community's Seventh Framework Programme (FP7/2007-2013) under Grant Agreement no. 212492 (CLARIS LPB - A Europe-South America network for climate change assessment and impact studies in La Plata Basin).

\section{References}

[1] Intergovernmental Panel on Climate Change- IPCC, Synthesis Report. Summary for Policymakers. Contribution of Working Group I, II and III to the Fourth Assessment Report of the Intergovernmental Panel on Climate Change, 2007.

[2] Intergovernmental Panel on Climate Change- IPCC, The Physical Science Basis. Summary for Policymakers. Working Group I Contribution to the Fifth Assessment Report of the Intergovernmental Panel on Climate Change, 2013.

[3] N. Nakicenovic and R. Swart, Eds., IPCC Special Report on Emissions Scenarios, vol. 599, Cambridge University Press, Cambridge, UK, 2000.

[4] C. Vera, W. Higgins, J. Amador et al., "Toward a unified view of the American monsoon systems," Journal of Climate, vol. 19, no. 20, pp. 4977-5000, 2006.

[5] R. J. Bombardi and L. M. V. Carvalho, "Variabilidade do regime de monções sobre o Brasil: o clima presente e projeções para um cenário com $2 \mathrm{xCO} 2$ usando o modelo MIROC", Revista Brasileira de Meteorologia, vol. 23, pp. 58-72, 2008.

[6] R. J. Bombardi and L. M. V. Carvalho, "IPCC global coupled model simulations of the South America monsoon system," Climate Dynamics, vol. 33, no. 7-8, pp. 893-916, 2009.

[7] A. Seth, M. Rojas, and S. A. Rauscher, "CMIP3 projected changes in the annual cycle of the South American Monsoon," Climatic Change, vol. 98, no. 3, pp. 331-357, 2010. 
[8] M. C. Valverde and J. A. Marengo, "Mudanças na circulação atmosférica sobre a América do sul para cenários futuros de clima projetados pelos modelos globais do IPCC AR4," Revista Brasileira de Meteorologia, vol. 25, pp. 125-145, 2010.

[9] R. E. Dickinson, R. M. Errico, F. Giorgi, and G. T. Bates, "A regional climate model for the western United States," Climatic Change, vol. 15, no. 3, pp. 383-422, 1989.

[10] F. Giorgi and L. O. Mearns, "Approaches to the simulation of regional climate change: a review," Reviews of Geophysics, vol. 29, no. 2, pp. 191-216, 1991.

[11] A. Seth, S. A. Rauscher, S. J. Camargo, J.-H. Qian, and J. S. $\mathrm{Pal}$, "RegCM3 regional climatologies for South America using reanalysis and ECHAM global model driving fields," Climate Dynamics, vol. 28, no. 5, pp. 461-480, 2007.

[12] J.-P. Boulanger, G. Brasseur, A. F. Carril et al., "A Europe-South America network for climate change assessment and impact studies," Climatic Change, vol. 98, no. 3, pp. 307-329, 2010.

[13] S. A. Solman, E. Sanchez, P. Samuelsson et al., "Evaluation of an ensemble of regional climate model simulations over South America driven by the ERA-Interim reanalysis: model performance and uncertainties," Climate Dynamics, vol. 41, pp. 1139-1157, 2013.

[14] S. A. Solman, "Regional climate modeling over south america: a review," Advances in Meteorology, vol. 2013, Article ID 504357, 13 pages, 2013.

[15] J. A. Marengo, T. Ambrizzi, R. P. da Rocha et al., "Future change of climate in South America in the late twenty-first century: intercomparison of scenarios from three regional climate models," Climate Dynamics, vol. 35, no. 6, pp. 1089-1113, 2010.

[16] L. F. Krüger, R. P. da Rocha, M. S. Reboita, and T. Ambrizzi, "RegCM3 nested in HadAM3 scenarios A2 and B2: projected changes in extratropical cyclogenesis, temperature and precipitation over the South Atlantic Ocean," Climatic Change, vol. 113, no. 3-4, pp. 599-621, 2012.

[17] J. A. Marengo, S. C. Chou, G. Kay et al., "Development of regional future climate change scenarios in South America using the Eta CPTEC/HadCM3 climate change projections: climatology and regional analyses for the Amazon, São Francisco and the Paraná River basins," Climate Dynamics, vol. 38, no. 910, pp. 1829-1848, 2012.

[18] S. A. Solman, M. N. Nuñez, and M. F. Cabré, "Regional climate change experiments over southern South America. I: present climate," Climate Dynamics, vol. 30, no. 5, pp. 533-552, 2008.

[19] M. N. Nuñez, S. A. Solman, and M. F. Cabré, "Regional climate change experiments over southern South America. II: climate change scenarios in the late twenty-first century," Climate Dynamics, vol. 32, no. 7-8, pp. 1081-1095, 2009.

[20] C. Gordon, C. Cooper, C. A. Senior et al., "The simulation of SST, sea ice extents and ocean heat transports in a version of the Hadley Centre coupled model without flux adjustments," Climate Dynamics, vol. 16, no. 2-3, pp. 147-168, 2000.

[21] V. D. Pope, M. L. Gallani, P. R. Rowntree, and R. A. Stratton, "The impact of new physical parametrizations in the Hadley Centre climate model: HadAM3," Climate Dynamics, vol. 16, no. 2-3, pp. 123-146, 2000.

[22] T. C. Johns, J. M. Gregory, W. J. Ingram et al., "Anthropogenic climate change for 1860 to 2100 simulated with the HadCM3 model under updated emission scenarios," Hadley Centre Technical Note, no. 22, p. 62, 2001.

[23] E. Roeckner, G. Bäuml, L. Bonaventura et al., The Atmospheric General Circulation Model ECHAM 5. Part I: Model Description,
Max Planck Institute for Meteorology, Hamburg, Germany, 2003.

[24] S. J. Marsland, H. Haak, J. H. Jungclaus, M. Latif, and F. Röske, "The Max-Planck-Institute global ocean/sea ice model with orthogonal curvilinear coordinates," Ocean Modelling, vol. 5, no. 2, pp. 91-127, 2002.

[25] F. Giorgi, M. R. Marinucci, and G. T. Bates, "Development of a second-generation regional climate model (RegCM2). Part I: boundary-layer and radiative transfer processes," Monthly Weather Review, vol. 121, no. 10, pp. 2794-2813, 1993.

[26] F. Giorgi, M. R. Marinucci, G. T. Bates, and G. De Canio, "Development of a second-generation regional climate model (RegCM2). Part II: convective processes and assimilation of lateral boundary conditions," Monthly Weather Review, vol. 121, no. 10, pp. 2814-2832, 1993.

[27] J. S. Pal, F. Giorgi, X. Bi et al., "Regional climate modeling for the developing world: The ICTP RegCM3 and RegCNET," Bulletin of the American Meteorological Society, vol. 88, no. 9, pp. 13951409, 2007.

[28] F. Giorgi and L. O. Mearns, "Introduction to special section: regional climate modeling revisited," Journal Geophysical Research, vol. 104, pp. 6335-6352, 1999.

[29] F. Giorgi, C. Jones, and G. Asrar, "Addressing climate information needs at the regional level: The CORDEX framework," WMO Bulletin, vol. 58, no. 3, pp. 175-183, 2009.

[30] R. E. Dickinson, A. Henderson-Sellers, and P. J. Kennedy, Biosphere-Atmosphere Transfer Scheme (BATS) Version $1 E$ As Coupled to the NCAR Community Climate Model, vol. 72, Technical Note NCAR/TN-387, Boulder, Colo, USA, 1993.

[31] R. P. Da Rocha, S. V. Cuadra, M. S. Reboita, L. F. Kruger, T. Ambrizzi, and N. Krusche, "Effects of RegCM3 parameterizations on simulated rainy season over South America," Climate Research, vol. 52, no. 1, pp. 253-265, 2012.

[32] A. A. M. Holtslag, E. I. F. De Bruijn, and H.-L. Pan, "A high resolution air mass transformation model for short-range weather forecasting," Monthly Weather Review, vol. 118, no. 8, pp. 1561-1575, 1990.

[33] G. A. Grell, "Prognostic evaluation of assumptions used by cumulus parameterizations," Monthly Weather Review, vol. 121, no. 3, pp. 764-787, 1993.

[34] T. R. Loveland, B. C. Reed, J. F. Brown et al., "Development of a global land cover characteristics database and IGBP DISCover from $1 \mathrm{~km}$ AVHRR data," International Journal of Remote Sensing, vol. 21, no. 6-7, pp. 1303-1330, 2000.

[35] E. Kalnay, M. Kanamitsu, R. Kistler et al., "The NCEP/NCAR 40-year reanalysis project," Bulletin of the American Meteorological Society, vol. 77, no. 3, pp. 437-471, 1996.

[36] S. M. Uppala, P. W. Kållberg, A. J. Simmons et al., "The ERA40 re-analysis," Quarterly Journal of the Royal Meteorological Society, vol. 131, no. 612, pp. 2961-3012, 2005.

[37] M. New, M. Hulme, and P. Jones, "Representing twentiethcentury space-time climate variability. Part II: development of 1901-96 monthly grids of terrestrial surface climate," Journal of Climate, vol. 13, no. 13, pp. 2217-2238, 2000.

[38] P. Xie and P. A. Arkin, "Global precipitation: a 17-year monthly analysis based on gauge observations, satellite estimates, and numerical model outputs," Bulletin of the American Meteorological Society, vol. 78, no. 11, pp. 2539-2558, 1997.

[39] D. R. Legates and C. J. Willmott, "Mean seasonal and spatial variability in global surface air temperature," Theoretical and Applied Climatology, vol. 41, no. 1-2, pp. 11-21, 1990. 
[40] W. Li and R. Fu, "Transition of the large-scale atmospheric and land surface conditions from the dry to the wet season over amazonia as diagnosed by the ECMWF re-analysis," Journal of Climate, vol. 17, pp. 2637-2651, 2004.

[41] M. A. Gan, V. B. Rao, and M. C. L. Moscati, "South American monsoon indices," Atmospheric Science Letters, vol. 6, no. 4, pp. 219-223, 2006.

[42] C. S. Ramage, Monsoon Meteorology, Academic Press, New York, NY, USA, 1971.

[43] J. Zhou and K.-M. Lau, "Does a monsoon climate exist over South America?" Journal of Climate, vol. 11, no. 5, pp. 1020-1040, 1998.

[44] J. D. Lenters and K. H. Cook, "Summertime precipitation variability over South America: role of the large-scale circulation," Monthly Weather Review, vol. 127, no. 2-3, pp. 409-431, 1999.

[45] M. S. Reboita, M. A. Gan, R. P. da Rocha, and T. Ambrizzi, "Regimes de precipitação na América do sul: uma revisão bibliográfica," Revista Brasileira de Meteorologia, vol. 25, pp. 185-204, 2010.

[46] J. A. Marengo, B. Liebmann, A. M. Grimm et al., "Recent developments on the South American monsoon system," International Journal of Climatology, vol. 32, no. 1, pp. 1-21, 2012.

[47] V. E. Kousky, "Pentad outgoing longwave radiation climatology for the South American sector," Revista Brasileira de Meteorologia, vol. 3, pp. 217-231, 1988.

[48] B. Liebmann and J. A. Marengo, "Interannual variability of the rainy season and rainfall in the Brazilian Amazon Basin," Journal of Climate, vol. 14, no. 22, pp. 4308-4318, 2001.

[49] Y. Kodama, "Large-scale common features of subtropical precipitation zones (the Baiu frontal zone, the SPCZ, and the SACZ). Part I: characteristics of subtropical frontal zones," Journal of the Meteorological Society of Japan, vol. 70, pp. 813835, 1992.

[50] L. M. V. Carvalho, C. Jones, and B. Liebmann, “The South Atlantic convergence zone: intensity, form, persistence, and relationships with intraseasonal to interannual activity and extreme rainfall," Journal of Climate, vol. 17, no. 1, pp. 88-108, 2004.

[51] M. S. Reboita, R. P. da Rocha, T. Ambrizzi, and S. Sugahara, "South Atlantic Ocean cyclogenesis climatology simulated by regional climate model (RegCM3)," Climate Dynamics, vol. 35, no. 7, pp. 1331-1347, 2010. 

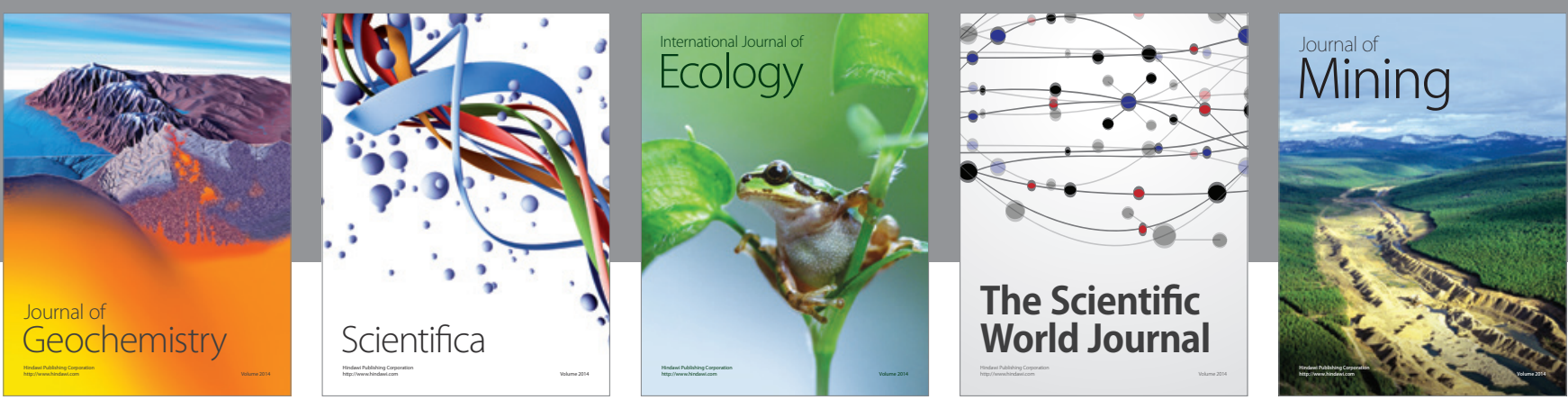

The Scientific World Journal
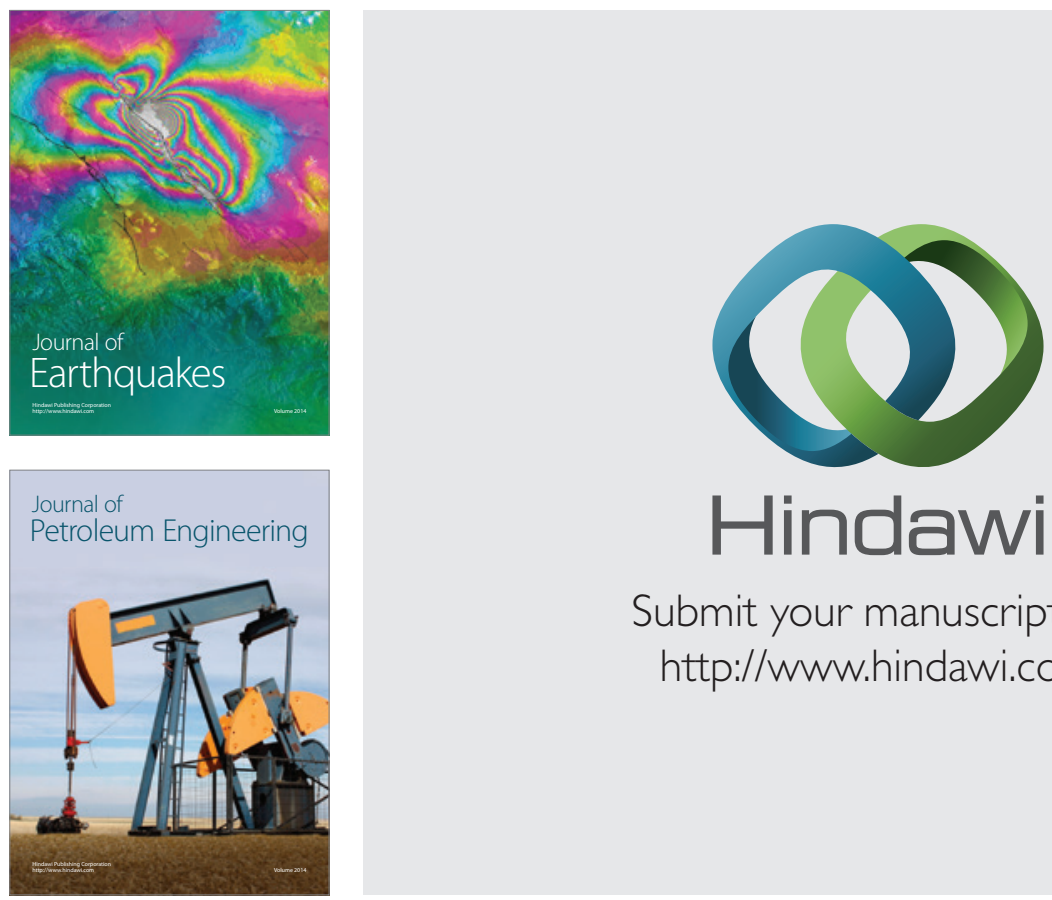

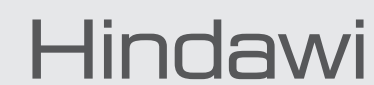

Submit your manuscripts at

http://www.hindawi.com
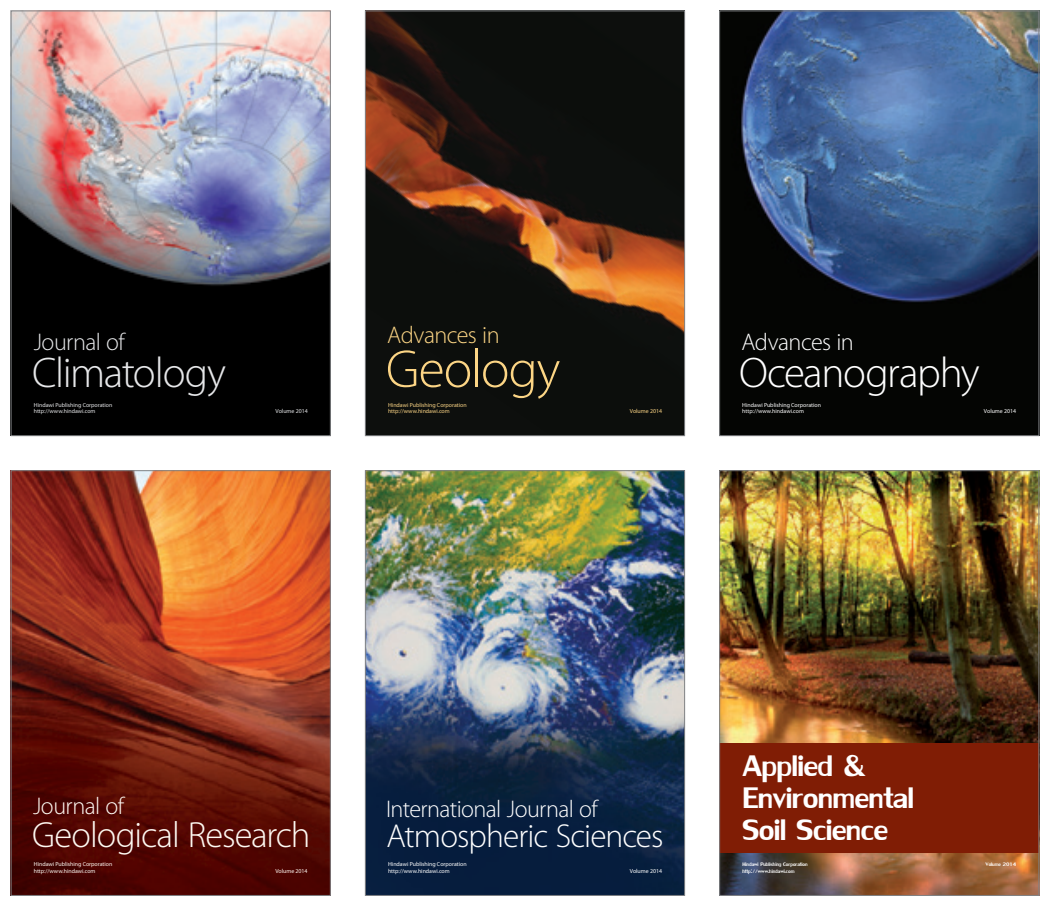
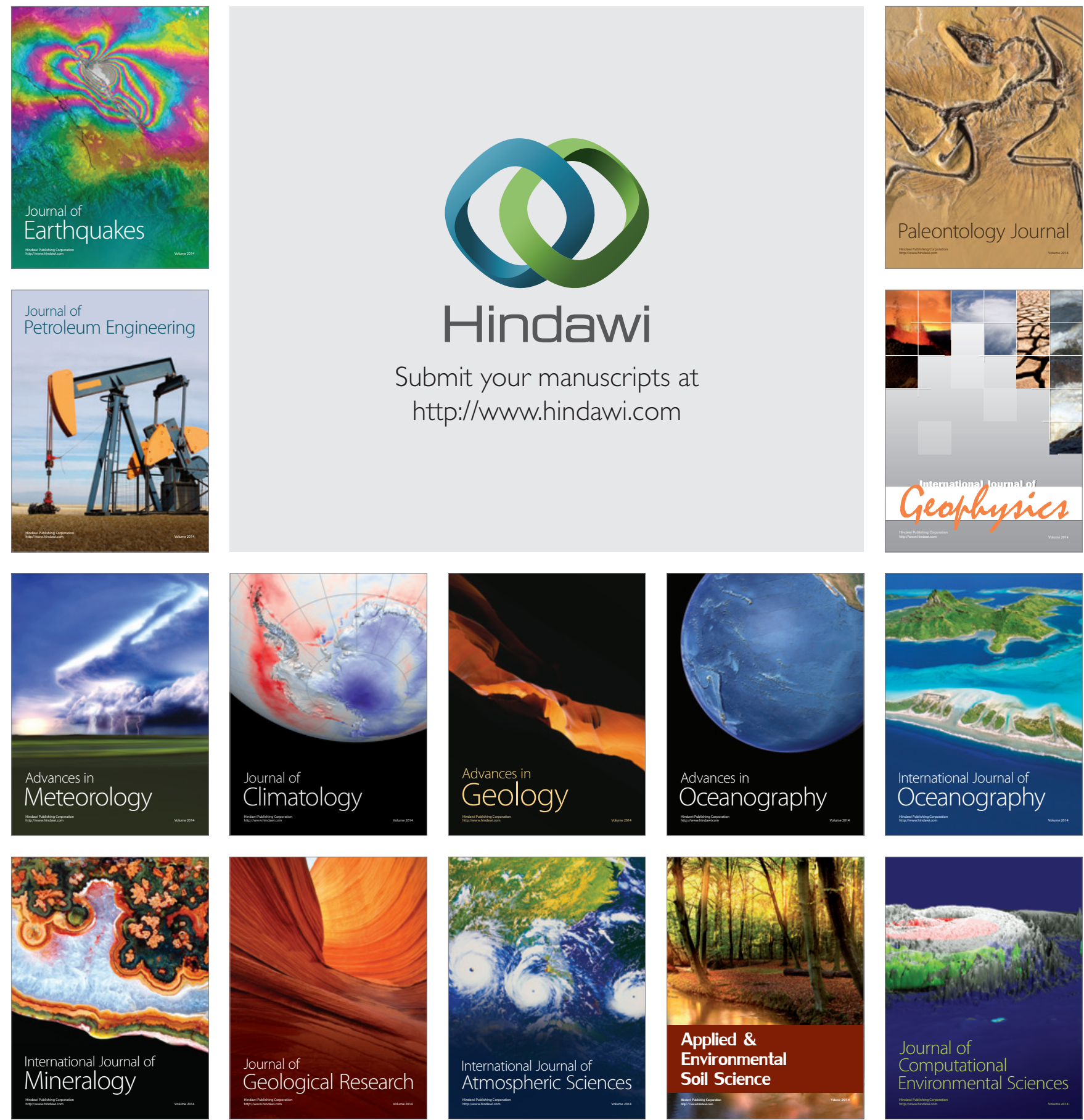